\title{
Storage Behavior of "Seddik" Mango Fruit Coated with CMC and Guar Gum-Based Silver Nanoparticles
}

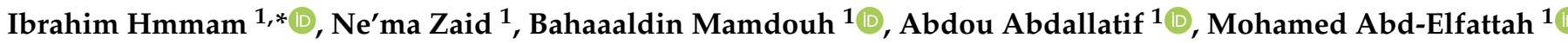 \\ and Mohamed Ali ${ }^{2}$ (D) \\ 1 Pomology Department, Faculty of Agriculture, Cairo University, Giza 12613, Egypt; \\ zaidneama@yahoo.com (N.Z.); bahaaaldin.m@agr.cu.edu.eg (B.M.); abdo.abdullatif@agr.cu.edu.eg (A.A.); \\ dr.mohamed.alaa@cu.edu.eg (M.A.-E.) \\ 2 Biochemistry Department, Faculty of Agriculture, Cairo University, Giza 12613, Egypt; bio90m@gmail.com \\ * Correspondence: ibrahim.s.hmmam@agr.cu.edu.eg
}

check for

updates

Citation: Hmmam, I.; Zaid, N.; Mamdouh, B.; Abdallatif, A.; Abd-Elfattah, M.; Ali, M. Storage Behavior of "Seddik" Mango Fruit Coated with CMC and Guar Gum-Based Silver Nanoparticles Horticulturae 2021, 7, 44 https://doi.org/10.3390/ horticulturae7030044

Academic Editors: Douglas D. Archbold and Elazar Fallik

Received: 14 January 2021 Accepted: 24 February 2021

Published: 4 March 2021

Publisher's Note: MDPI stays neutral with regard to jurisdictional claims in published maps and institutional affiliations.

Copyright: (c) 2021 by the authors. Licensee MDPI, Basel, Switzerland. This article is an open access article distributed under the terms and conditions of the Creative Commons Attribution (CC BY) license (https:/ / creativecommons.org/licenses/by/ $4.0 /)$

\begin{abstract}
Mango fruit (cv. Seddik) is known as a delicate fruit for storage after harvest. Herein, carboxymethyl cellulose (CMC) and guar gum-based silver nanoparticles (AgNPs) were used as fruit coatings, and their effects on postharvest storage behavior and quality attributes were investigated. AgNPs were synthesized using a chemical reduction approach and then combined with CMC and guar gum as coating bases. Mango fruits were coated with the developed and pre-characterized CMC-AgNPs and guar gum-AgNPs, and then packed and stored at $13{ }^{\circ} \mathrm{C}$ for 4 weeks. The results showed an increase in weight loss, respiration rate, total soluble solids (TSS), total sugars, and total carotenoids over the storage period. However, this increase was comparatively less significant in coated fruits compared to uncoated fruits. Firmness and titratable acidity (TA) significantly decreased during storage, but this decrease was less in coated fruits. Silver traces in fruit pulp samples were not detected. These findings showed the efficacy of CMC-AgNP and guar gum-AgNP coatings in delaying mango fruit ripening and maintaining fruit quality during cold storage. Therefore, these coatings could be promising alternative materials for extending the postharvest life and marketing period of mango fruit.
\end{abstract}

Keywords: mango; edible coating; carboxymethyl cellulose (CMC); guar gum; nanoparticles; cold storage

\section{Introduction}

Mango (Mangifera indica L.), a climacteric fruit, is considered the most economically important fruit crop in tropical and subtropical regions. It is harvested at the hard, green mature stage and ripens rapidly at ambient temperature [1]. The attractive appearance, intense aroma, delicious taste and flavor, and the high nutritional value of mango fruit (from vitamins, antioxidants, phenolic compounds, $\beta$-carotene, amino acids, minerals, and dietary fiber) have been well characterized [2,3]. Acceptance of mango fruit by consumers is highly correlated with both external and internal quality factors [4], and these factors are mainly determined by the flavor resulting from sugars, acids, and aroma volatile compounds [5].

Mango fruits are highly perishable with limited postharvest life through rapid ripening, weight loss, texture softening, conversion of starch to sugars, and decay [6,7]. Poor postharvest handling, disease incidence, and sensitivity to chilling injury contribute to high postharvest and marketing chain losses and reduce the storage period $[6,8,9]$. These losses can exist at all postharvest stages, from harvest to consumption [10]. In developing countries where mango fruit handling and storage techniques are not ideal, postharvest losses of mango fruit may be more than 50\% due to physiological and pathological disorders [6,11]. One of the most popular mango cultivars in Egypt is "Seddik", but it is known as a delicate mango fruit to store for a long period after harvest. Hence, postharvest practices play a pivotal role in controlling mango fruit losses by applying proper, safe, 
and effective treatments during fruit harvest, handling, and storage in order to extend the postharvest shelf-life period [6,12].

One practical technique for extending the storage period is fruit coating to enhance the appearance and improve fruit quality $[9,13]$. Edible coatings are natural eco-friendly biodegradable products, mainly composed of polysaccharides, proteins, lipids, or a blend of these compounds $[12,14,15]$. Edible coatings with natural origin such as polysaccharides, the most widely used, are considered as a safe strategy for fruit preservation $[12,16,17]$. Polysaccharide-based edible coatings such as cellulose derivatives and pectin are highly stable, safe, nontoxic, and biodegradable [15]. Edible coatings have also been exploited to incorporate antimicrobial and antisenescence agents $[14,18]$.

Carboxymethylcellulose (CMC) is a cellulose derivative extracted from plant cell walls composed of linear anionic chains of glucopyranosyl units with high molecular weight [19]. CMC has many food industry applications because it is nontoxic, nonallergenic, odorless, tasteless, biocompatible, and biodegradable [16,19]. CMC-based coatings are also transparent and slightly permeable to $\mathrm{O}_{2}, \mathrm{CO}_{2}$, and moisture [20]. Edible coatings based on CMC have been effective in preserving the postharvest quality of papaya (Carica papaya) [21], mandarin (Citrus reticulata) [22], and plum (Prunus domestica) [17].

Guar gum is a natural polysaccharide derived from guar bean seeds [23] and can also be used as an edible coating due to its high molecular weight, long polymeric chain, content of natural antioxidants and bioactive compounds, good availability, and ability to enhance water solubility [24]. A guar gum coating can be used commercially to extend the shelf life of fruit because it is biodegradable, easy to use, and low-cost [25]. Guar gum-based coatings have recently been used to preserve the postharvest quality of mango [26] and Valencia orange (Citrus sinensis) [27].

The application of nanotechnology is a new technique for extending the shelf life of fresh fruit [28]. Nanoparticles can be used for fruit preservation due to their unique physical and chemical characteristics in addition to antimicrobial properties [29,30]. Recently, the use of coating materials loaded with nanoparticles has represented an innovative and safe fruit preservation technique that guarantees less direct exposure and minimal penetration of nanoparticles into treated food products [31]. Silver nanoparticles (AgNPs) have been receiving the most attention from the research community due to their remarkable properties in size and efficient antibacterial activities [32,33]. AgNPs have been used as food additives and packaging materials to eliminate pathogens [28,34]. Edible coating formulations combined with silver nanoparticles can be used for coating edible fruit to inhibit the growth of microorganisms that cause postharvest diseases, thereby increasing their shelf life [20,35]. Many experiments have focused on the structural characteristics and bioactivity of nanocomposites as fruit coatings [36,37]. Nevertheless, it is essential to further investigate their applicability as a coating on the basis of the fruit's physicochemical and physiological responses.

Obviously, most previous studies focused on evaluating the application of different coating materials to mango fruit, but so far there are no published data on the application of coatings loaded with AgNPs to enhance the storage behavior of mango fruit, especially the fruit of the local mango cultivar "Seddik", which is known to be stored for only short period after harvest. Moreover, the studies that focused on the cold storage behavior and quality attributes of this local cultivar are few. Herein, we hypothesized that different nanobased coating materials would enhance the storage behavior and the quality attributes of "Seddik" mango fruit. Therefore, the present investigation aimed at evaluating the effects of the developed and pre-characterized CMC and guar gum-based AgNPs coatings on postharvest storage behavior and quality attributes of "Seddik" mango fruit.

\section{Materials and Methods}

\subsection{Chemicals}

All chemicals used in this study were reagent-grade and purchased from different companies worldwide. For instance, ethanol $\left(\mathrm{C}_{2} \mathrm{H}_{5} \mathrm{OH}, 100 \%\right)$, sodium chloride $(\mathrm{NaCl}$, 
99.8\%), and sodium hypochlorite $\left(\mathrm{NaClO} / \mathrm{H}_{2} \mathrm{O}, 12 / 13 \%\right)$ were purchased from Chem-Lab (Zedelgem, Belgium); $\mathrm{CMC}$, guar gum, beeswax, and sodium borohydride $\left(\mathrm{NaBH}_{4}, 97 \%\right)$ were purchased from LOBA Chemie PVT. LTD. (Mumbai, India); lecithin was purchased from Neogen (Lansing, MI, USA); silver nitrate $\left(\mathrm{AgNO}_{3}, 99.9 \%\right)$ was purchased from Merck (Darmstadt, Germany); polyvinylpyrrolidone was purchased from CARLO ERBA Reagents S.A.S. (Val de Reuil Cedex, France). All solutions were prepared with deionized water unless otherwise stated.

\subsection{Preparation of CMC and Guar Gum-Based Silver Nanoparticles Coatings \\ 2.2.1. Preparation of Coating Base}

A coating emulsion base was prepared according to a method previously reported by Shah et al. [35] with slight modification. The following steps describe this method: $10 \mathrm{~g}$ of lecithin, $50 \mathrm{~g}$ of olive oil, and $200 \mathrm{~mL}$ of $0.85 \%$ saline water $(0.85 \mathrm{~g} \mathrm{NaCl}$ dissolved in $100 \mathrm{~mL}$ deionized water) were first combined and mixed well by constant stirring at room temperature. Then, beeswax $(1 \mathrm{~g})$ was added and the stirring temperature was increased to $65^{\circ} \mathrm{C}$ with constant stirring. For each coating emulsion base, $150 \mathrm{~mL}$ of CMC solution $(2 \%, w / v)$ and guar gum solution $(2 \%, w / v)$ were prepared in separate flasks and shaken vigorously for emulsion formation. After the addition of $6.7 \mathrm{~mL}$ of sodium hypochlorite, the volume of each coating base was made up to $1000 \mathrm{~mL}$ using $0.85 \%$ saline water.

\subsubsection{Preparation of Silver Nanoparticles}

The silver nanoparticles were synthesized using the chemical reduction method of An et al. [28] with slight modification. First, solutions of silver nitrate $(0.1 \mathrm{M})$, sodium borohydride $(0.01 \mathrm{M})$, and polyvinylpyrrolidone (PVP $2 \%, w / v)$ were separately prepared. Then, a 1:1 volume ratio of sodium borohydride and PVP was mixed well and cooled in an ice bath for $30 \mathrm{~min}$ under constant stirring. After that, the silver nitrate solution was added to this mixture dropwise until a brown color formed, indicating the formation of silver nanoparticles.

\subsubsection{Preparation of $\mathrm{CMC}$ and Guar Gum-Based Silver Nanoparticle Coatings}

The above-prepared coating emulsion bases of $\mathrm{CMC}$ and guar gum were separately mixed with the prepared silver nanoparticle solution in a 1:1 ratio [35] to form a CMCbased silver nanoparticle coating (CMC-AgNPs) and a guar gum-based silver nanoparticle coating (guar gum-AgNPs).

\subsection{Characterization of AgNPs and CMC and Guar Gum-Based Silver Nanoparticle Coatings}

\subsubsection{Ultraviolet (UV)/Visible Light (Vis) Spectroscopy}

The AgNPs, CMC-AgNPs, and guar gum-AgNPs were characterized using a UV/Vis spectrophotometer (T80, PG Instruments Ltd., Leicestershire, UK) in the central lab of the Biochemistry Department, Faculty of Agriculture, Cairo University. The scanning range for the samples was $300-700 \mathrm{~nm}$. Milli-Q water was used as a blank reference.

\subsubsection{Transmission Electron Microscopy (TEM)}

A morphological analysis, including the size and shape, of the synthesized nanoparticles was determined using transmission electron microscopy (JEOL JEM-1400, Peabody, MA, USA) at a bias voltage of 40-120 kV at the Cairo University Research Park (CURP). A drop (2 uL) of Milli-Q water, which dissolved synthesized nanoparticles, was placed on a carbon grid (C-grid). The size was obtained by measuring the diameter of particles present in the TEM image.

\subsubsection{Fourier-Transform Infrared (FTIR)}

The CMC coating base, guar gum coating base, CMC-AgNPs, and guar gum-AgNPs were characterized using a Fourier-transform infrared spectrophotometer (Thermo Scientific NICOLET 380 FT-IR, Waltham, MA, USA) at the Cairo University Research Park 
(CURP). A sample (2 mg) was combined with potassium bromide (100 mg) and compacted to prepare a salt disc with a diameter of approximately $3 \mathrm{~mm}$. The disc was immediately placed in the holder of the sample. FTIR spectra were detected in the absorption range between 400 and $4000 \mathrm{~cm}^{-1}$.

\subsection{Fruit Material}

Freshly harvested "Seddik" mango fruits were obtained from a commercial mango orchard grown under well-managed conditions and located in Al-Sharkiya Governorate, Egypt. All fruits were picked on 21 July at a physiologically mature stage early in the morning and were transported to the postharvest laboratory of the Pomology Department, Faculty of Agriculture, Cairo University, within $2 \mathrm{~h}$ of harvest. All fruits were carefully washed with tap water and then kept at ambient temperature to dry. Mature, uniformly sized mango fruits free of mechanical damage were selected for coating application.

\subsection{Coating Application and Storage Conditions}

Mango fruits were divided into three treatments, each containing 60 fruits. The first treatment group was immersed into CMC-AgNP coating material for $30 \mathrm{~s}$ and the second treatment group was immersed into guar gum-AgNP coating material for $30 \mathrm{~s}$. The third group was left without coating as a control. There were three biological replicates in each treatment, and each replication had 20 fruits. All mango fruits were packed in carton boxes, 10 fruits in each, and stored in a cold chamber at $13^{\circ} \mathrm{C}$ with $85-90 \%$ relative humidity. The cold chamber was disinfected using sodium hypochlorite solution followed by ethanol $(70 \%, v / v)$ at the beginning of the storage period. Over the storage period, a fruit quality assessment of each treatment was carried out regularly after $0,7,14,21$, and 28 days.

\subsection{Fruit Quality Attributes}

\subsubsection{Weight Loss}

To calculate the weight loss in defined periods during storage, fruits $(n=10)$ of each treatment were periodically weighed using a digital balance to compare the difference between initial fruit weight (W1) and weight at sampling date (W2), and weight loss (\%) was calculated according to Shah and Hashmi [38] using the following equation:

$$
\text { Weight loss }(\%)=((W 1-W 2) / W 1) \times 100 .
$$

\subsubsection{Respiration Rate}

Three mango fruits of each treatment were separately incubated in $2 \mathrm{~L}$ airtight glass jars for $24 \mathrm{~h}$ at $13{ }^{\circ} \mathrm{C}$ to measure the respiration rate. The gas sampling was measured by analyzing carbon dioxide using a gas analyzer (Model Servomex1400; Servomex, East Sussex, UK). The respiration rate was calculated according to the equation provided by Pristijono et al. [39] and expressed as $\mathrm{nmol} \mathrm{CO} 2 \cdot \mathrm{kg}^{-1} \cdot \mathrm{s}^{-1}$.

\subsubsection{Fruit Pulp Firmness}

Fruit pulp firmness $(n=3)$ from each treatment was measured using a pressure firmness tester (L-10, AMETEK Inc., Lansdale, PA, USA) with a stainless-steel rod ( $8 \mathrm{~mm}$ diameter) and a displacement depth of $10 \mathrm{~mm}$. The entire fruit was placed on a flat surface, and firmness was measured on the pared fruit surface in the equatorial zone. The results were expressed in $\mathrm{N}$ according to Liu et al. [40].

\subsubsection{Total Soluble Solids (TSS), Titratable Acidity (TA), and TSS/TA Ratio}

Mango fruit juice was extracted from three fruits per replicate to determine TSS and TA according to the method of Khaliq et al. [41]. TSS concentration was measured using a digital refractometer (Pocket refractometer PAL-1, Atago, Tokyo, Japan) and data were expressed as a percentage of TSS. The TA (\%) of the fruit pulp was measured by titrating a $10 \mathrm{~mL}$ aliquot of juice (1 mL juice $+9 \mathrm{~mL}$ distilled water) with $0.1 \mathrm{~N} \mathrm{NaOH}$ using 
phenolphthalein indicator and expressed as a percentage of citric acid equivalents on the basis of fresh weight. By dividing the TSS percentage with the corresponding acidity percentage, the TSS/TA ratio was calculated.

\subsubsection{Total Sugar Content}

Total sugar content was determined using the phenol-sulfuric acid method [42]. Fruit pulp samples ( $0.25 \mathrm{~g}$-collected from three fruits) were homogenized in $20 \mathrm{~mL}$ of $70 \%$ ethanol $(v / v)$ and filtered. The filtrates $(1 \mathrm{~mL})$ were treated with $1 \mathrm{~mL}$ of $5 \%$ phenol $(v / v)$ and $5 \mathrm{~mL}$ of $98 \%$ sulfuric acid $(v / v)$. After $1 \mathrm{~h}$, the absorbance of the cold and colored solutions was read at $490 \mathrm{~nm}$ using UV/Vis spectrophotometer (UNICO S2100, Cole Parmer Instruments, Chicago, IL, USA). A standard curve was generated using a standard glucose solution, and total sugar content was expressed as mg glucose equivalents per $\mathrm{g}$ fresh weight.

\subsubsection{Total Carotenoid Content}

Fruit pulp samples ( $0.25 \mathrm{~g}$-collected from three fruits) were homogenized in $20 \mathrm{~mL}$ of $80 \%$ acetone $(v / v)$ for carotenoid extraction. Extracts were filtered and absorbance was measured using a UV / Vis spectrophotometer (UNICO S2100, Cole Parmer Instruments, Chicago, IL, USA) at 480 and $510 \mathrm{~nm}$. Total carotenoid content was calculated according to Jensen [43] as $\mu \mathrm{g} \cdot \mathrm{g}^{-1}$ of fresh weight using the following formula:

$$
\text { Total Carotenoids }\left(\mu \mathrm{g} \cdot \mathrm{g}^{-1}\right)=7.6(O D 480)-1.49(O D 510) \times(V / 1000) \times(W),
$$

where $O D=$ optical density, $V=$ final volume of $80 \%$ acetone, and $W=$ sample weight.

\subsubsection{Determination of Total Silver Concentration}

Samples of coated fruit (CMC-AgNPs and guar gum-AgNPs) at 14 and 28 days of storage were digested in an acid solution $(70 \%$ nitric acid $+30 \%$ hydrogen peroxide $(v / v)$ using a microwave digestion system (Multi-wave PRO, Anton-Paar, Graz, Austria) according to the method of Altundag and Tuzen [44]. All samples were digested to provide an acceptable matrix for assessing silver ions and having adequate and reliable recovery compatible with the analytical method. The silver content was determined according to Zhang et al. [45]. The silver concentration was calculated using inductively coupled plasma optical emission spectrometry (5100 ICP-OES, Agilent, Santa Clara, CA, USA) in an atomic spectroscopy lab, National Research Center, Giza, Egypt.

\subsection{Statistical Analysis}

The experiment was carried out in a completely randomized design with three replications. The model assumptions of normality were tested using Shapiro-Wilk's test $(P \leq 0.05)$ to perform an appropriate ANOVA. When these assumptions were not satisfied, data were transformed to ensure that the residuals followed an approximately normal distribution for further analysis. Statistical analysis was performed with normalized data, but all results are shown as original data. Two-way analysis of variance (ANOVA) was performed to investigate the effect of coating treatment, storage time, and their interaction. Significant differences $(\alpha \leq 0.05)$ were determined using Duncan's multiple range [46] test using the general linear model (GLM) procedure-SAS software Version 9.0 (SAS Institute Inc., Cary, NC, USA). Results were plotted as the mean \pm standard error (SE) using SigmaPlot (version 14.0, Systat Software, Inc., San Jose, CA, USA). A linear model of regression was used to describe the storage time-related change in fruit quality attributes. Correlation analysis was also performed for analyzing the association between fruit quality parameters during storage using Pearson's test $(P \leq 0.05$ and $P \leq 0.01)$. Principal component analysis (PCA) was applied using XLSTAT (Addinsoft, New York, NY, USA) to identify relationships between factors (coating treatments, storage time, and their interaction) and fruit quality parameters. 


\section{Results and Discussion}

3.1. Characterization of AgNPs and CMC and Guar Gum-Based Silver Nanoparticle Coatings 3.1.1. UV/Vis Spectroscopy

The UV/Vis spectrum of AgNPs (Figure 1) was recorded as a function of wavelength using a UV/Vis spectrophotometer. AgNPs exhibit peaks of absorption between 300 and $700 \mathrm{~nm}$. The UV/Vis spectrum of the synthesized AgNPs had a maximum absorbance at $447 \mathrm{~nm}$ (Figure 1). The $420 \mathrm{~nm}$ wide absorption band is typical of AgNPs, and it is attributable to plasmon surface resonance excitation [47,48]. This single peak of the plasmon surface resonance (PSR) revealed that the AgNPs were spheres with a broad size distribution. Furthermore, other researchers confirmed the PSR peak between 410 and $450 \mathrm{~nm}$ as a sign of AgNP synthesis [49,50]. The absorption spectrum of $\mathrm{Ag}^{+} / \mathrm{CMC}$ showed a shift in wavelength where the absorbance value decreased, and the UV/Vis spectrum of $\mathrm{Ag}^{+} /$guar gum was also in the same range as that of $\mathrm{Ag}^{+} / \mathrm{CMC}$ (data not shown). This is probably due to the interaction of $\mathrm{CMC}$ with $\mathrm{Ag}^{+}$ions, although plasmon absorption of nanosilver also occurs [51,52], which may be assigned to a $\pi \rightarrow \pi^{*}$ transition derived from carbonyl groups $(\mathrm{C}=\mathrm{O})$ or ethylene unsaturated bonds $(=\mathrm{C}=\mathrm{C}=)$ of the type $(-\mathrm{CH}=\mathrm{CH}-)$ $\mathrm{CO}$ in the CMC structure $[53,54]$.

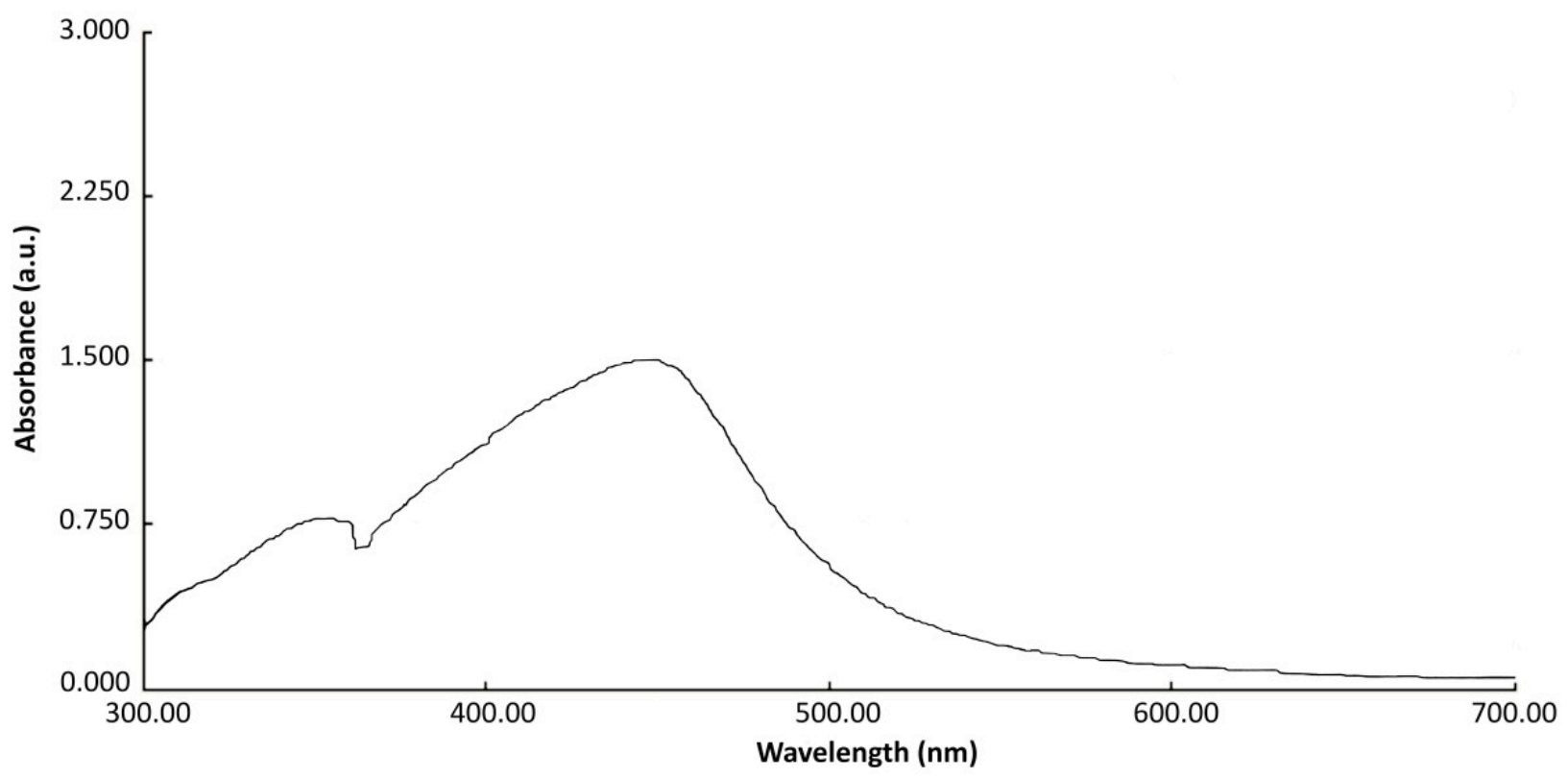

Figure 1. Ultraviolet (UV)/visible light (Vis) spectrum of the synthesized silver nanoparticles (AgNPs).

\subsubsection{Transmission Electron Microscopy}

TEM images of the synthesized silver nanoparticles (dark spherical objects) are shown in Figure 2a. Their size ranged from $5.84 \mathrm{~nm}$ to $10.2 \mathrm{~nm}$. TEM images revealed that nanoparticles were formed at sizes ranging from 84.8 to $213 \mathrm{~nm}$ for CMC-AgNPs and 61.7 to $132 \mathrm{~nm}$ for guar gum-AgNPs (Figure $2 \mathrm{~b}, \mathrm{c}$ ). The size measured was greater than that measured for AgNPs due to the polymeric matrix of CMC and guar gum. The TEM images indicated that the AgNPs were spherical in shape and well scattered in the solution, and the nanoparticles were separated from each other without any aggregation. 

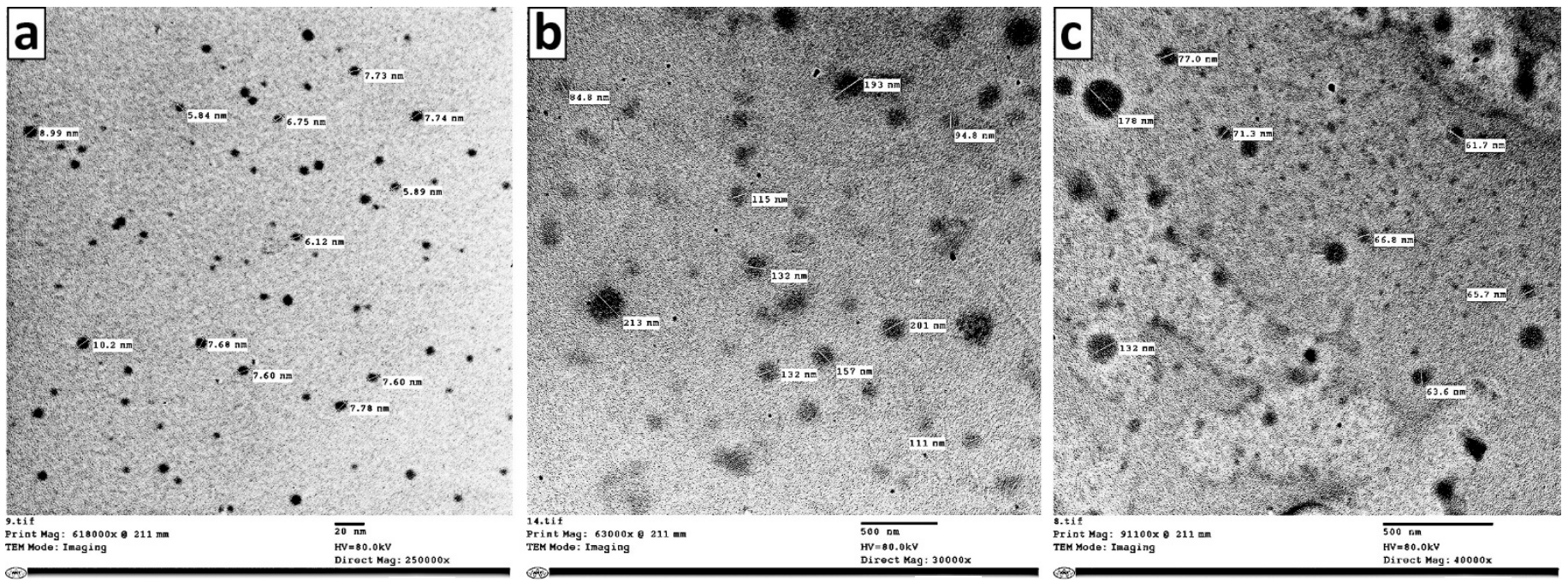

Figure 2. The transmission electron microscope (TEM) micrographs of (a) AgNPs, (b) carboxymethyl cellulose (CMC)AgNPs, and (c) guar gum-AgNPs.

\subsubsection{Fourier-Transform Infrared}

The FTIR spectrum of the CMC coating base showed peaks at 3449.21, 2852.25, 2065.95, $1637.17,1458.11,1045.05$, and $494.43 \mathrm{~cm}^{-1}$ (Figure 3). The broad peak at $3449.21 \mathrm{~cm}^{-1}$ indicated the existence of the $-\mathrm{OH}$ stretching vibration of $\mathrm{CMC}$, while the peaks observed around 2852.25 and $1045.05 \mathrm{~cm}^{-1}$ may be assigned to $\mathrm{C}-\mathrm{H}$ stretching and $-\mathrm{OH}$ bending vibration, respectively. The observed bands in the CMC coating base at 3449.21 and $2852.25 \mathrm{~cm}^{-1}$ were shifted to a higher wave number and became sharper in CMC-AgNPs due to the interaction of AgNPs with the-OH group of CMC. The bands detected at 1637.17 and $1458.11 \mathrm{~cm}^{-1}$ may be related to the carboxylate anion in the symmetric mode in CMC and olive oil $[55,56]$.

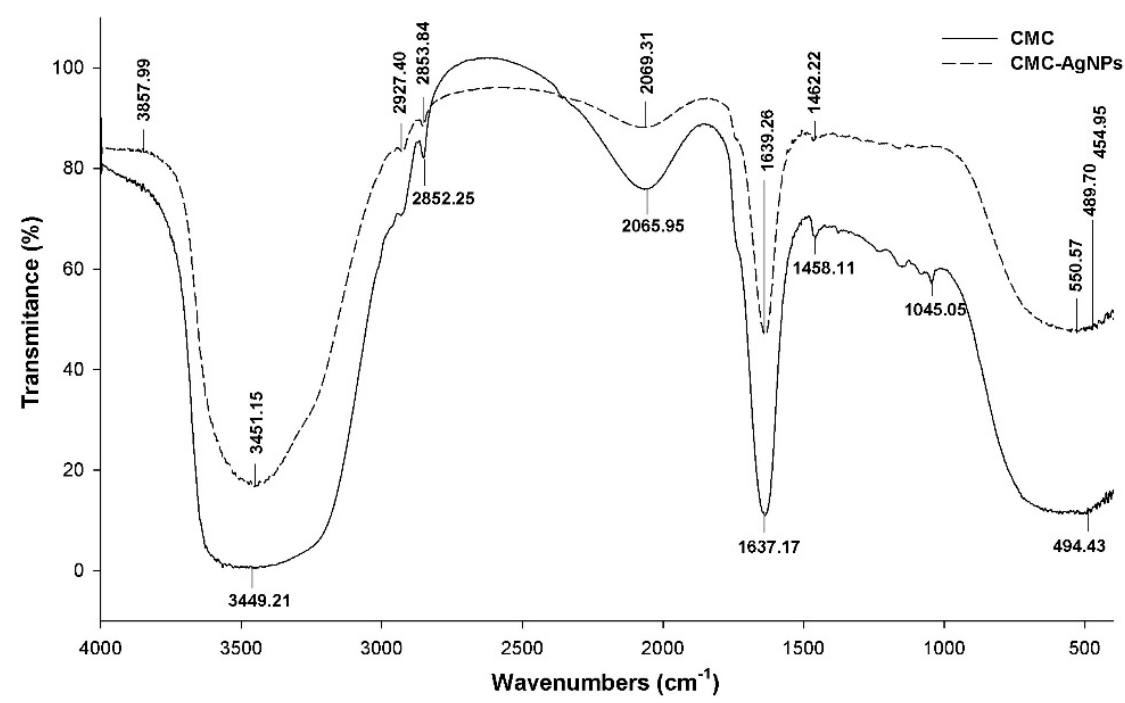

Figure 3. Fourier-transform infrared (FTIR) absorption spectra of CMC coating base (solid line) and CMC-AgNPs (dashed line).

FTIR spectra of the guar gum coating base and guar gum-AgNPs are shown in Figure 4 . The FTIR spectrum of the guar gum coating base showed peaks at 3455.67, 2042.88, 1637.81, $1535.12,1458.82$, and $509.10 \mathrm{~cm}^{-1}$. The first sizeable peak at $3455.67 \mathrm{~cm}^{-1}$ demonstrated the existence of guar gum -OH stretching vibration, while the peak at $1458.82 \mathrm{~cm}^{-1}$, attributed to the symmetrical deformation of the $-\mathrm{CH}_{2}$ group, was of negligible intensity. The band 
detected at $1637.81 \mathrm{~cm}^{-1}$ is related to the carboxylate anion in symmetric mode of the coating base. In guar gum-AgNPs, the observed peak at $3453.64 \mathrm{~cm}^{-1}$ shifted to a lower IR frequency value than the corresponding peak in the guar gum coating base. This probably indicated an interaction of AgNPs with the $-\mathrm{OH}$ group of guar gum. The presence of metal-oxygen bond participation in the biopolymer blend nanocomposite was clearly defined by the peak at $584.30 \mathrm{~cm}^{-1}$. Metal ions, such as silver, have a strong affinity to form coordination bonds with guar gum polar $-\mathrm{OH}$ groups. With increasing concentrations of AgNPs, the interaction between silver nanoparticles and the oxygen atom of the $-\mathrm{OH}$ group became more robust. Due to this interaction, the position and peaks of IR spectra of guar gum-AgNPs (Figure 4) changed as compared to the guar gum coating base. The shifting and broadness of the detected bands in the case of guar gum-AgNPs gave evidence of the presence of AgNPs inside the polymer matrix [57].

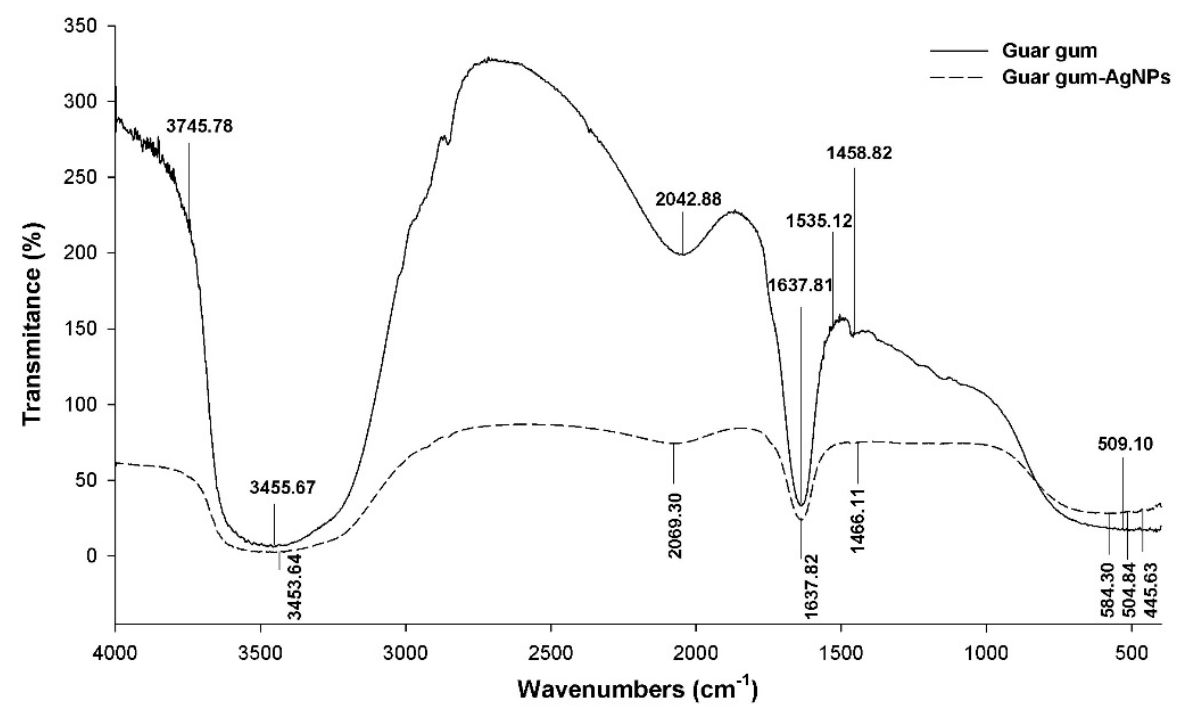

Figure 4. FTIR spectra of guar gum coating base (solid line) and guar gum-AgNPs (dashed line).

\subsection{Fruit Quality Attributes}

\subsubsection{Weight Loss}

Mango fruit weight loss increased progressively in all treatments over the storage period of 28 days, as shown in Figure 5. The weight loss values were significantly affected by storage period $(\alpha \leq 0.05)$. The regression analysis showed that the fruit weight loss followed a linear increment during fruit storage. The high value of coefficient of determination indicated the existence of a strong relationship between weight loss and storage period (Table S1, Supplementary Materials), and the slope of the weight loss regression equation was higher in the control treatment $\left(\beta_{1}=0.7304 ; R^{2}=0.9987\right)$ than for fruits coated with CMC-AgNPs $\left(\beta_{1}=0.5973 ; R^{2}=0.9995\right)$ and guar gum-AgNPs $\left(\beta_{1}=0.5043 ; R^{2}=0.9994\right)$. However, coatings markedly controlled weight loss during storage, particularly with the guar gum-AgNP coating compared to CMC-AgNP coating and uncoated fruits (control) over the storage period. Maximum weight loss was observed in uncoated fruits $(20.48 \%)$ after 4 weeks of storage at $13{ }^{\circ} \mathrm{C}$, while, on the same date, the weight loss values of coated fruits with CMC-AgNPs and guar gum-AgNPs were $16.57 \%$ and $14.03 \%$, respectively. Water loss results in changes in texture, shrinkage, and other physical properties of the fruit, thus reducing the quality value of fresh fruit and affecting shelf life [58]. Mature climacteric fruits undergo a series of metabolic processes, such as transpiration and respiration, when detached from the tree; the correlation between weight loss and respiration rate was highly positive, while it was strongly negatively correlated with pulp firmness (Table S2, Supplementary Materials). These metabolic processes eventually result in fruit weight loss during the postharvest and storage period [9,59]. The coating material can mitigate the loss of water and reduce these deleterious effects by acting as a barrier of 
moisture between the fruit and the environment around it. Moreover, polymeric coating films with efficient water vapor barriers can reduce the movement of water vapor from the stomata of fruit peels (reducing fruit transpiration) and maintaining the turgidity of cell walls [60]. Another study also reported that fresh weight preservation in fruits treated with films was reinforced with nanoparticles [61].

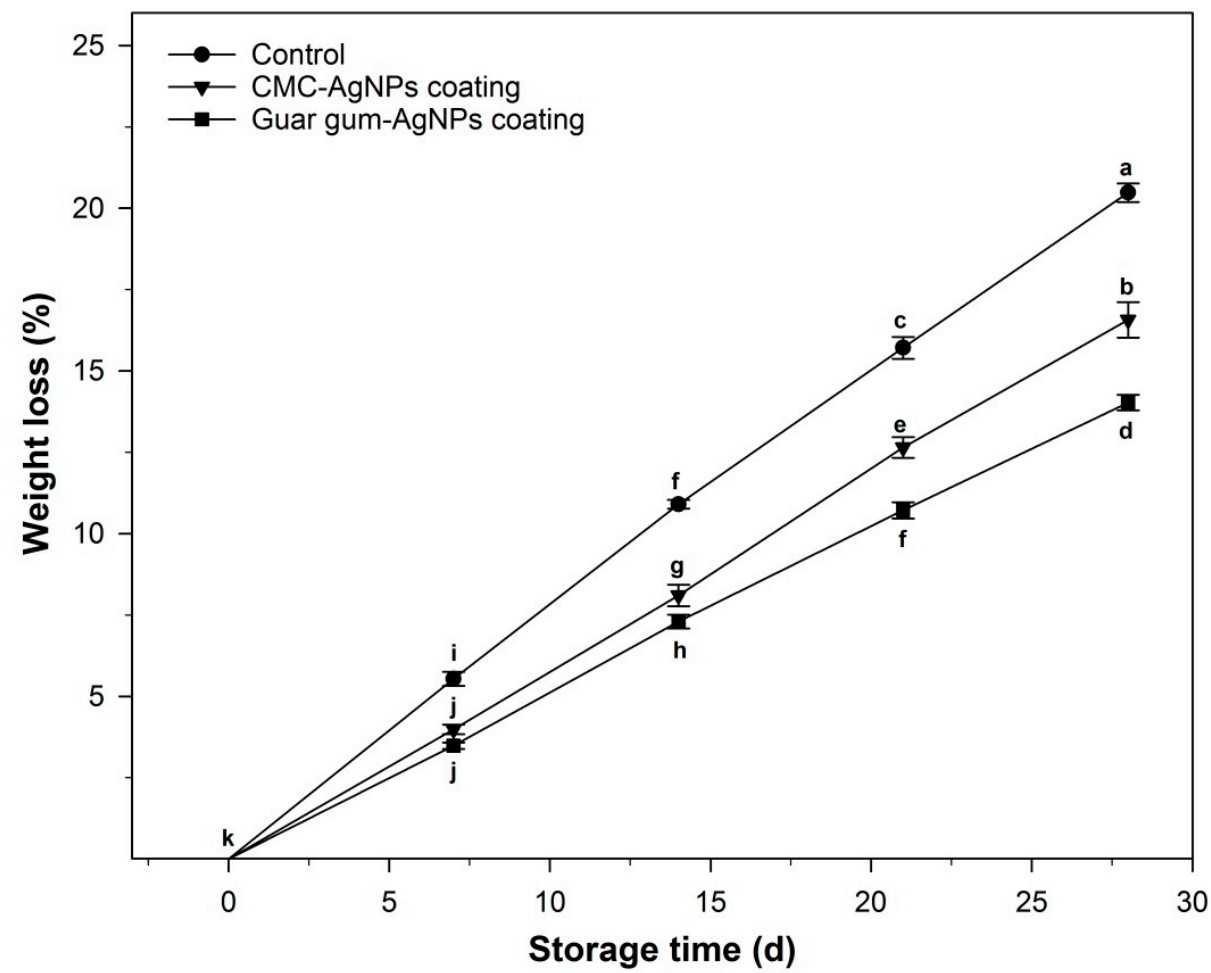

Figure 5. Effect of CMC-AgNPs and guar gum-AgNPs coatings on weight loss of "Seddik" mango fruits stored at $13^{\circ} \mathrm{C}$ for 4 weeks. Vertical bars represent the standard error (SE) of means. Means with the same letter are not significantly different according to Duncan's multiple range test $(\alpha \leq 0.05)$.

\subsubsection{Respiration Rate}

The respiration rate of fresh fruit, such as mango fruit, is a good indicator for estimating storage behavior. The change in respiration rate of mango fruits with or without coatings is represented in Figure 6. A significant increase in the respiration rate was recorded for both coated and control treatment fruits during the storage period. Respiration rate increased linearly during the storage period. The positive relationship between respiration rate and storage time was highly dependent on coating treatment (Table S1, Supplementary Materials). The regression equation of control fruits had a higher slope $\left(\beta_{1}=22.11 ; R^{2}=0.7408\right.$, not significant (NS)), while coating treatments recorded lower respiration rates during the storage period with slight differences in regression equation slopes (10.1947; $R^{2}=0.7845$, for guar gum-AgNPs and $16.484 ; R^{2}=0.7741$ for CMC-AgNPs). The lowest respiration rate values were observed for guar gum-AgNP-coated fruits followed by those coated with CMC-AgNPs. Respiration rates of control and coated fruits with CMC-AgNPs and guar gum-AgNPs were low during the first 21 days of storage; afterward, they exhibited a sharp increase with values equal to $7.83 \times 10^{2}, 5.91 \times 10^{2}$, and $3.87 \times 10^{2} \mathrm{nmol} \mathrm{CO} 2 \cdot \mathrm{kg}^{-1} \cdot \mathrm{s}^{-1}$, respectively (Figure 6). Respiration rates in the control were significantly and consistently greater than those in the coated fruits across the entirety of the storage period. Ripening in climacteric fruit such as mango is characterized by a significant and rapid increase in respiration rate accompanied by intensive metabolic changes [59]. The respiration rate was positively correlated with the increases in total sugar content in the fruit and with the total soluble solid content. Meanwhile, it had a strongly negative correlation with titratable acidity (Table S2, Supplementary Materials). The coat- 
ing materials operate as a semipermeable barrier to the exchange of gases, movement of solvents, and moisture, thus decelerating the rate of respiration, oxidation reactions, and weight loss [62]. Ultimately, uncoated fruits showed more rapid perishability than coated fruits. Silva et al. [58] also noticed an increase in the rate of mango fruit respiration with an increasing frequency of decay.

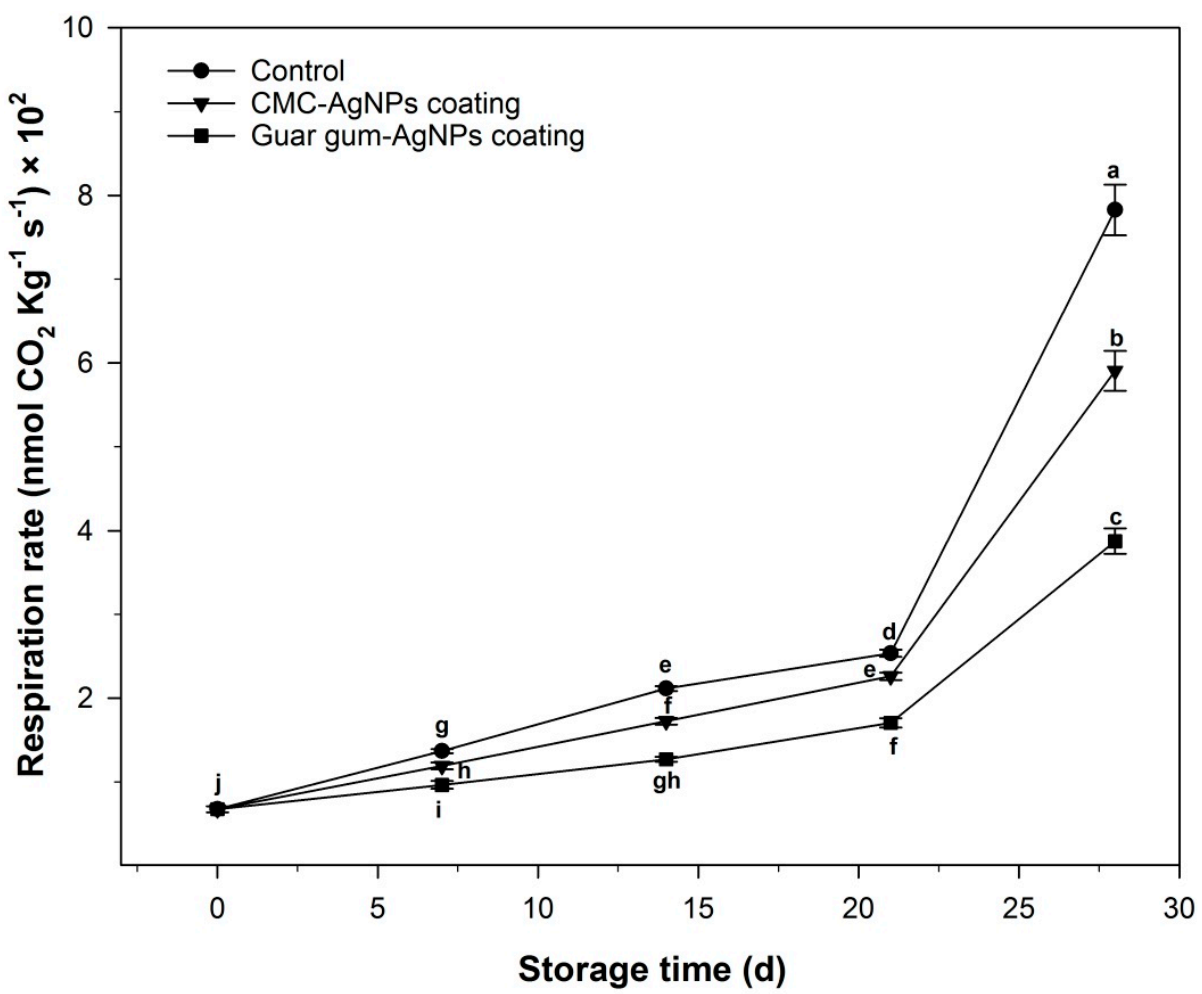

Figure 6. Effect of CMC-AgNP and guar gum-AgNP coatings on respiration rate of "Seddik" mango fruits stored at $13{ }^{\circ} \mathrm{C}$ for 4 weeks. Vertical bars represent the SE of means. Means with the same letter are not significantly different according to Duncan's multiple range test $(\alpha \leq 0.05)$.

\subsubsection{Fruit Pulp Firmness}

Fruit pulp firmness, an essential factor for the postharvest fruit quality, was found to be significantly decreased for all treatments over the storage period (Figure 7). The regression analysis showed that the fruit firmness decreased linearly during the fruit storage period. Regression equations described the changes in pulp firmness during the storage period for each coating treatment (Table S1, Supplementary Materials). The slope of the regression equations revealed that the fruit softening rate was slower in fruits coated with guar gum$\operatorname{AgNPs}\left(\beta_{1}=-1.0717 ; R^{2}=0.9751\right)$ and CMC-AgNPs $\left(\beta_{1}=-1.3854 ; R^{2}=0.9786\right)$ than the control treatment $\left(\beta_{1}=-1.6479 ; R^{2}=0.9841\right)$. The loss of firmness during storage is the most apparent textural change in fruit. Notably, the coating greatly postponed the loss of fruit firmness, and the maximum loss of firmness was found at the end of the storage period in the control fruits $(25.05 \mathrm{~N})$. Meanwhile, mango fruits coated with CMC-AgNPs and guar gum-AgNPs maintained higher firmness than the control with values equal to 33.21 and $42.25 \mathrm{~N}$, respectively, at the end of the storage period. Moreover, guar gumcoated fruits were significantly firmer than CMC-coated fruits. Mechanical properties of mango fruit such as firmness are fundamental for fruit handling, transport, storage, and consumer acceptability [63]. The maintenance of the pulp firmness of the coated fruits may be attributed to decreased respiration and other processes of ripening during storage, ultimately providing the fruit with greater firmness $[9,38]$. Coating material effectively slowed down the metabolic and enzymatic activities in the fruits, resulting in a slower degradation of pulp tissues. Obviously, the inhibition of respiratory metabolism related to the expression of enzyme activities, mostly polygalacturonase and pectin methylesterase 
responsible for fruit softening, has been associated with internal gaseous modification of the fruit caused by coatings $[64,65]$. Similar to the data of Silva et al. [58], a significant negative correlation was observed between fruit firmness and some of the biochemical parameters such as fruit respiration rate and total sugar content (Table S2, Supplementary Materials). Silver nanocomposite films effectively delayed mango softening during the storage period [66].

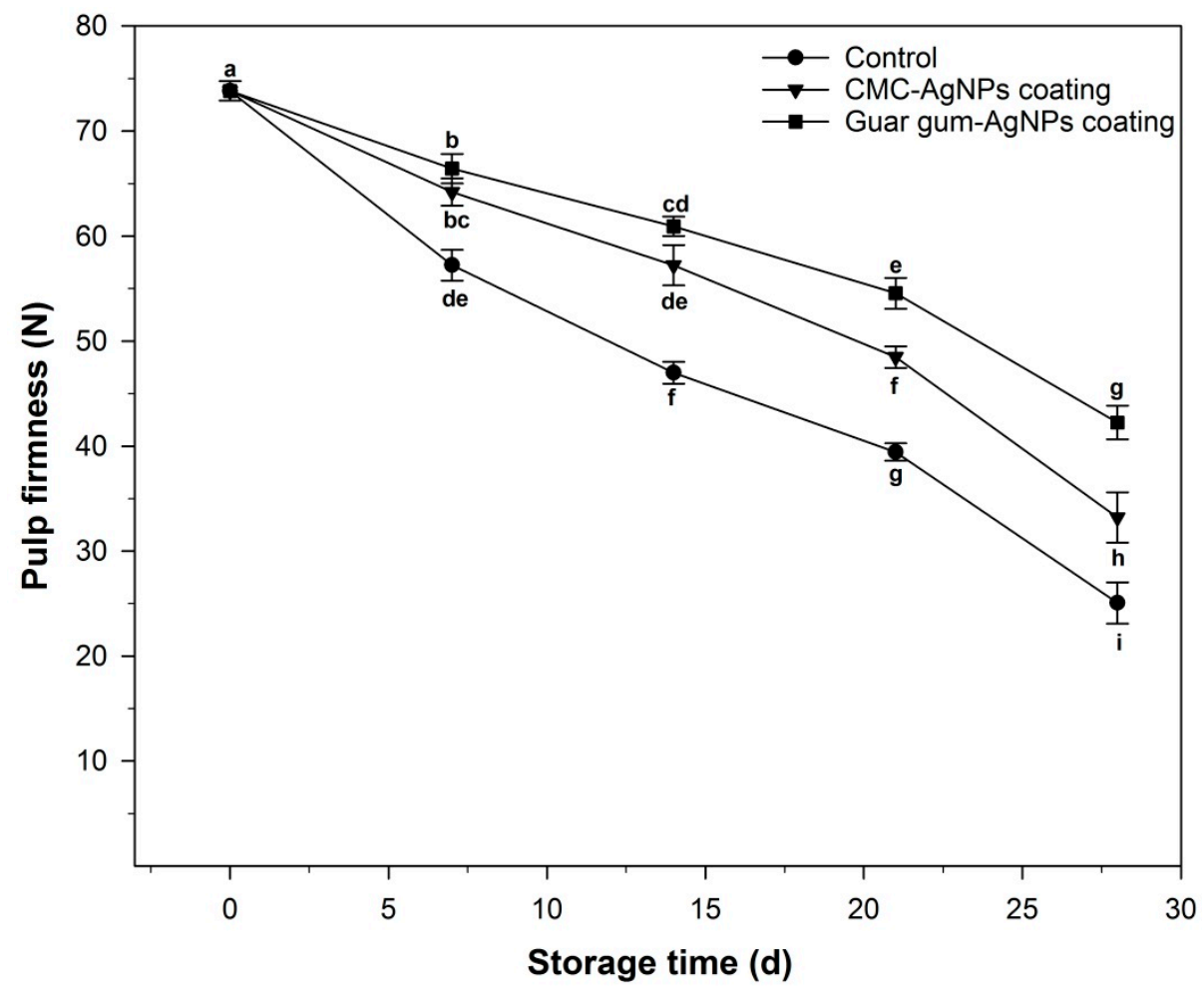

Figure 7. Effect of CMC-AgNP and guar gum-AgNP coatings on pulp firmness of "Seddik" mango fruits stored at $13{ }^{\circ} \mathrm{C}$ for 4 weeks. Vertical bars represent \pm SE of means. Means with the same letter are not significantly different according to Duncan's multiple range test $(\alpha \leq 0.05)$.

\subsubsection{Total Soluble Solids (TSS), Titratable Acidity (TA), and TSS/TA Ratio}

A gradual increase in total soluble solids (TSS) was observed as storage time progressed in all treatments (Figure 8). The increase was significantly lower in guar gumand CMC-coated fruits than the control fruits. Fruits coated with CMC-AgNPs recorded slightly higher, but not statistically evident, TSS values compared with guar gum-AgNPs up to 21 days of storage. Generally, the control treatment showed the highest significant TSS value (18.06\%) after 28 days of cold storage. Regression analysis showed that the TSS content increased linearly (Table S1, Supplementary Materials) during fruit storage. The predicted change in TSS content for mango fruits with different coating treatments could be estimated using the slope of the regression equation $\left(\beta_{1}=0.3889,0.3006\right.$, and 0.263 for the control, CMC-AgNPs, and guar gum-AgNPs, respectively) with the coefficient of determination $\left(R^{2}>0.95\right)$. During the storage period, the variation in TSS could be due to alterations of the cell wall and hydrolysis of complex carbohydrates by the activities of hydrolytic enzymes [67], which was shown by a highly negative correlation with pulp firmness and a strongly positive correlation with total sugar content (Table S2, Supplementary Materials). In previous studies on coated fruits, similar findings were also observed to decelerate the increase in TSS [35,60]. AgNPs-based coatings reduced the increase in TSS content of coated fruits compared with uncoated fruits during storage [35,68]. Gol et al. [69] suggested that the low TSS for coated fruits presumably occurred because of the barrier effect of coating against respiration and evaporation, thus decelerating the metabolic activities of the fruit. 


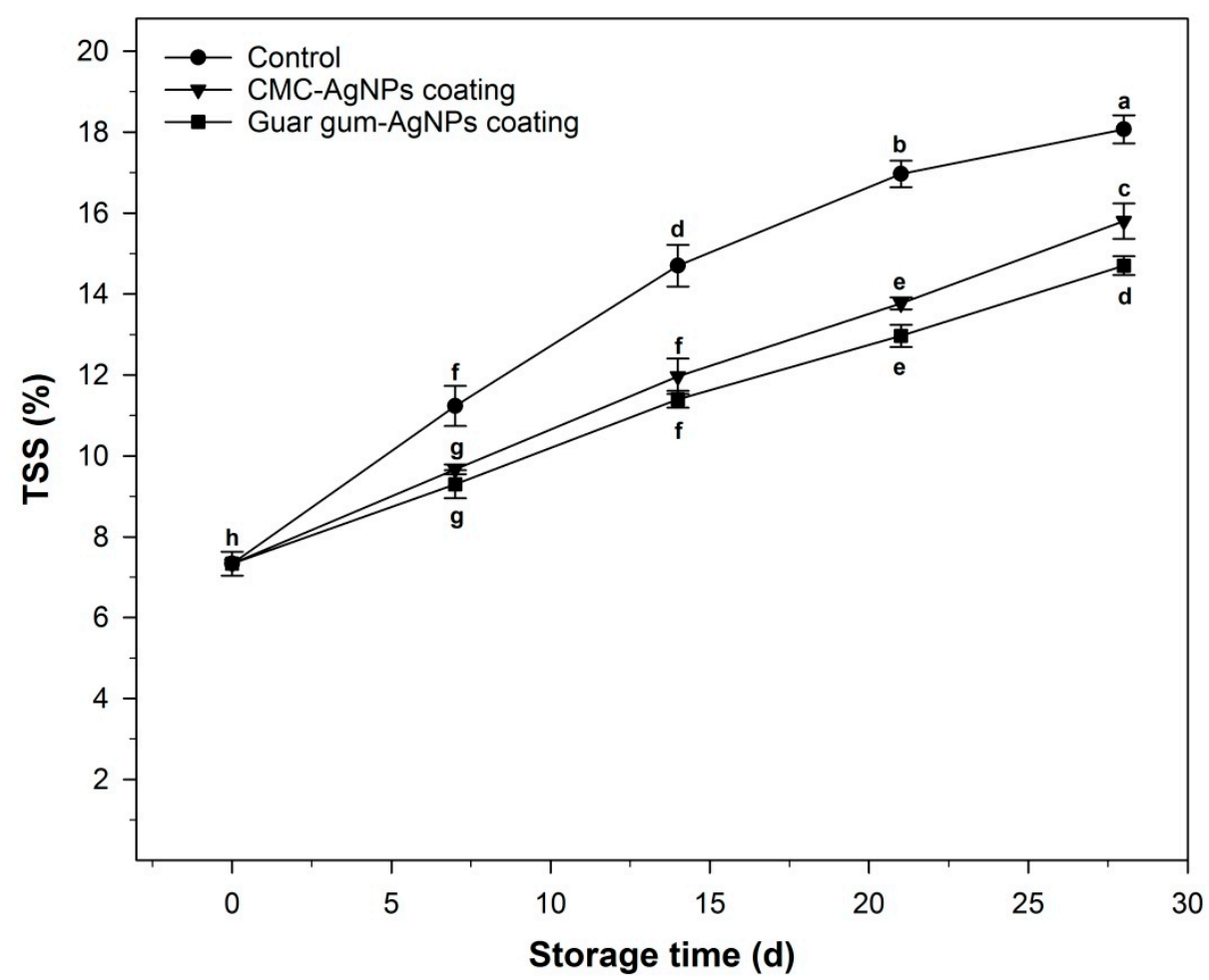

Figure 8. Effect of CMC-AgNP and guar gum-AgNP coatings on total soluble solids (TSS) of "Seddik" mango fruits stored at $13{ }^{\circ} \mathrm{C}$ for 4 weeks. Vertical bars represent the SE of means. Means with the same letter are not significantly different according to Duncan's multiple range test $(\alpha \leq 0.05)$.

A gradual decline was detected in titratable acidity (TA) for all treatments over the storage period of 28 days (Figure 9). The TA results illustrated that CMC-AgNP and guar gum-AgNP coatings reduced the declining trend for mango fruits, compared to the control during the storage period. Fruits coated with CMC- and guar gum-AgNPs recorded statistically similar TA values until the end of the storage period, while control fruits had significantly lower values. The decline in fruit acidity during fruit ripening is associated with a reduction in organic acids, such as citric or malic acid, which are known to be the primary substrates for the respiration process of climatic fruit, such that a decrease in acidity can be anticipated in highly respiratory fruit [70]. The regression analysis showed that titratable acidity was significantly affected by storage period. The negative slope values (Table S1, Supplementary Materials) indicated that TA tended to decrease during cold storage $\left(13^{\circ} \mathrm{C}\right)$. The slope $\left(\beta_{1}\right)$ of the regression equations of the coated fruit was very similar $\left(-0.7202 ; R^{2}=0.8024\right.$ for guar gum-AgNPs and $-0.7647 ; R^{2}=0.8959$ for CMC$\mathrm{AgNPs}$ ) and the change in TA was slower than for the control fruits. In line with the data of Silva et al. [58], changes in fruit acidity showed significant negative correlations $(P \leq 0.01)$ with several parameters such as weight loss, TSS, respiration rate, and total sugars with a correlation coefficient $(r)$ ranging from 0.614 to 0.911 (Table S2, Supplementary Materials). In other words, as previously mentioned, the application of coating decelerates the rate of respiration and metabolic processes that turn organic acid into sugars, thus limiting the excess increase of organic acids in respiration reactions [35]. 


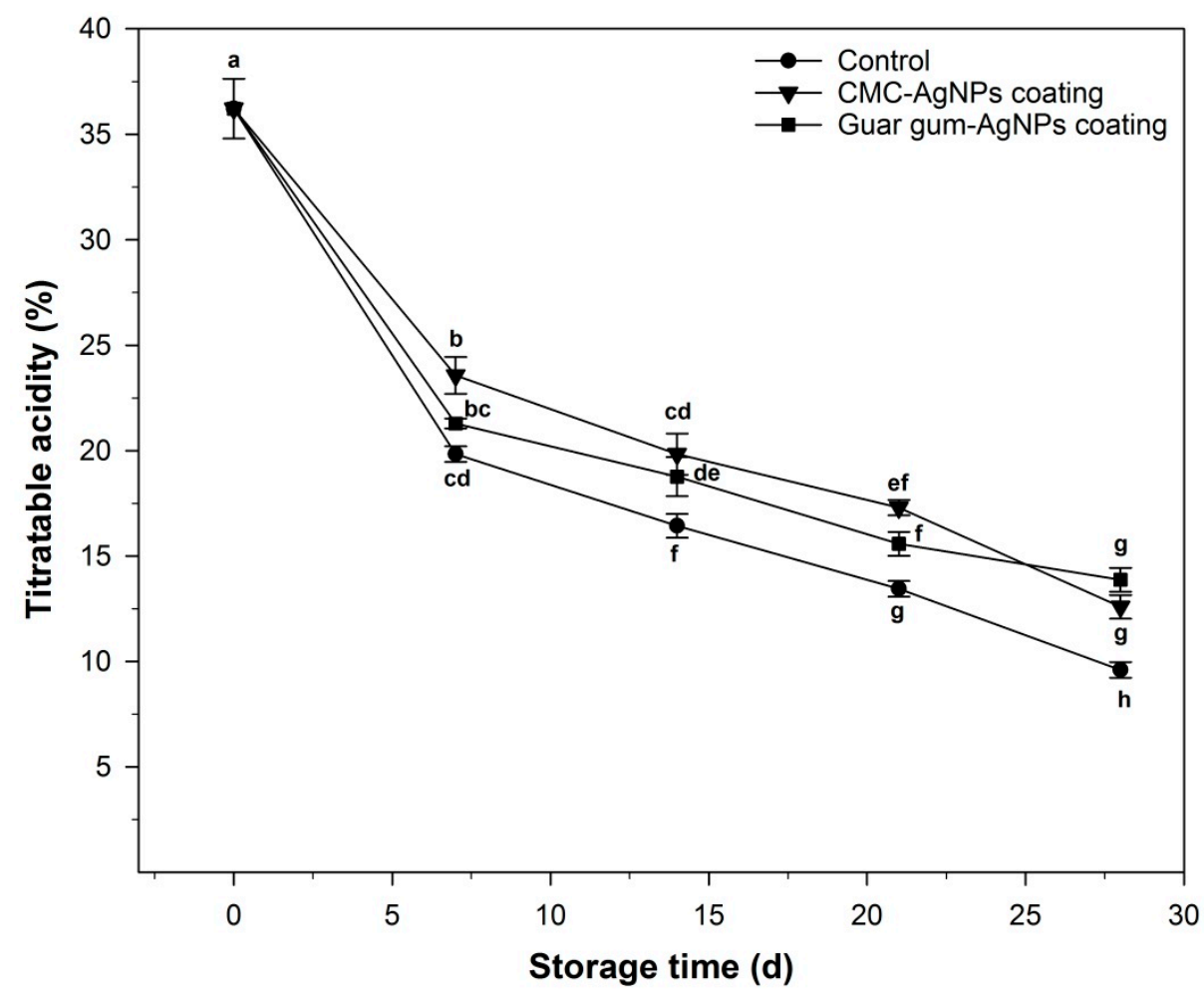

Figure 9. Effect of CMC-AgNP and guar gum-AgNP coatings on titratable acidity (TA) of "Seddik" mango fruits stored at $13{ }^{\circ} \mathrm{C}$ for 4 weeks. Vertical bars represent the SE of means. Means with the same letter are not significantly different according to Duncan's multiple range test $(\alpha \leq 0.05)$.

The TSS/TA ratio was significantly affected by coating treatments and storage period. The TSS/TA ratio values for all coated fruits were lower than those for the uncoated fruits (Figure 10). No difference was observed between CMC-AgNP and guar gum-AgNP coatings until 21 days of the storage period. However, the TSS/acidity ratio for CMCAgNP-coated mango was slightly higher after 28 days of storage. The TSS/TA ratio showed a rapid increase in uncoated fruits, indicating fruit ripening velocity. The ratio of TSS and TSS/TA is known to be an indicator of fruit quality. Linear regression analysis illustrated that the TSS/TA ratio increased linearly during fruit storage. Control fruits had a higher regression equation slope value $\left(\beta_{1}=0.05813 ; R^{2}=0.9819\right)$, while coating treatments recorded significantly lower slope values during the storage period with slight differences between coating types $\left(0.03026 ; R^{2}=0.9981\right.$ for guar gum-AgNPs and 0.03566 ; $R^{2}=0.9583$ for CMC-AgNPs) (Table S1, Supplementary Materials). As predicted, the TSS/TA ratio had significant correlations $(P \leq 0.01)$ with TSS and with titratable acidity (Table S2, Supplementary Materials). Inverse relationships were observed between TSS values and TA values of mango pulp as a result of the decrease in acidity for their further utilization in fruit metabolic process during ripening [67]. 


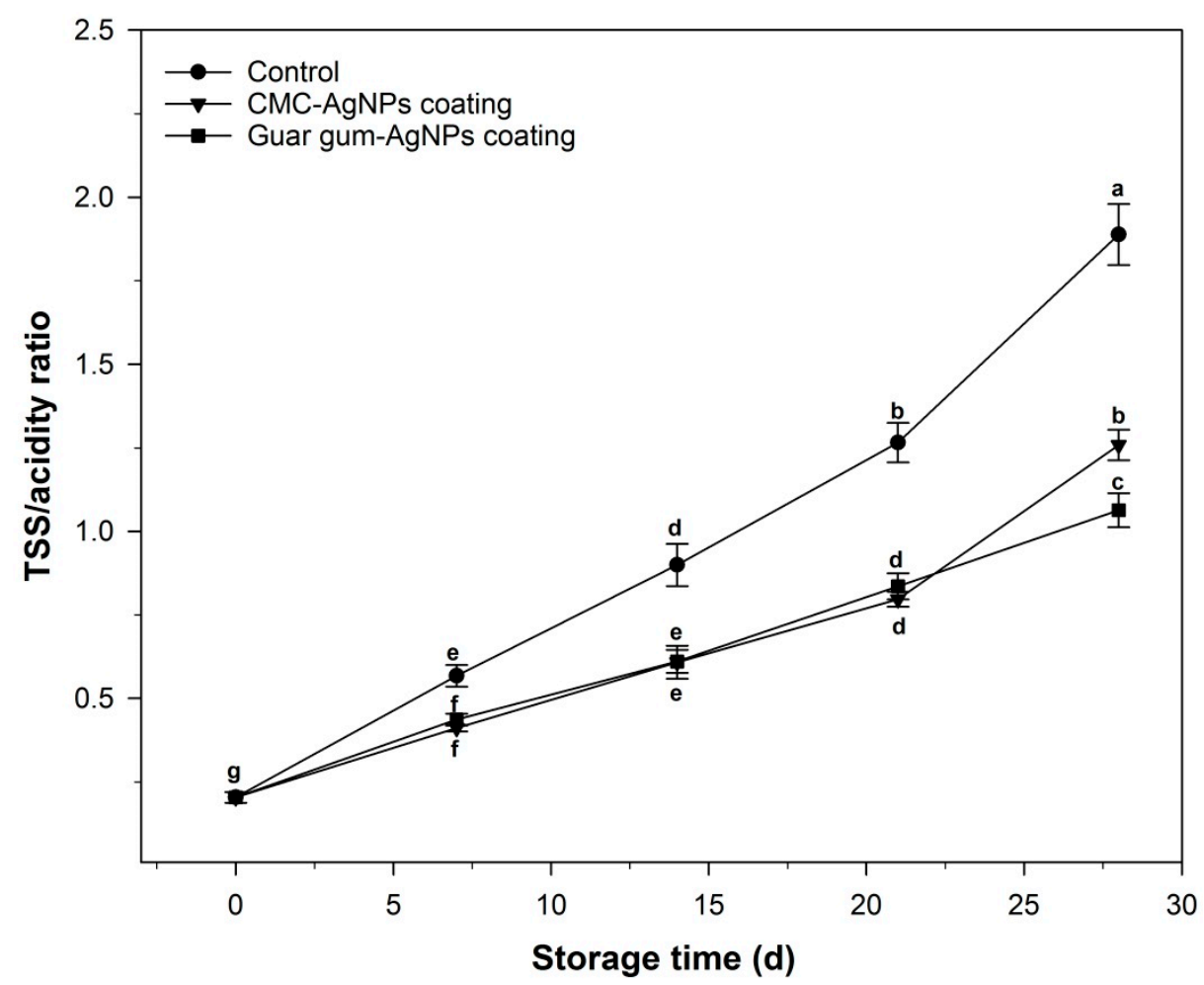

Figure 10. Effect of CMC-AgNP and guar gum-AgNP coatings on TSS/TA ratio of "Seddik" mango fruits stored at $13{ }^{\circ} \mathrm{C}$ for 4 weeks. Vertical bars represent the SE of means. Means with the same letter are not significantly different according to Duncan's multiple range test $(\alpha \leq 0.05)$.

\subsubsection{Total Sugar Content}

During the storage period, total sugars of coated fruit slowly increased (Figure 11). The highest total sugar content $\left(260.03 \mathrm{mg} \cdot \mathrm{g}^{-1}\right)$ was with the uncoated fruits after 28 days of storage. A linear relationship was found between total sugar content and the length of the storage period. The slope of the regression equations showed that total sugar content was affected by coating treatments $\left(\beta_{1}=6.7319,2.111\right.$, and 1.8499 for the control, CMC-AgNPs, and guar gum-AgNPs, respectively); the positive estimated $\beta_{1}$ values indicated that total sugar content tended to increase during cold storage $\left(13^{\circ} \mathrm{C}\right)$ (Table S1, Supplementary Materials). Total sugar content increased at a very slow rate in all fruits, while a sharp increase in uncoated fruits was observed after 21 days of storage. The total sugar content of the fruits coated with CMC-AgNPs and guar gum-AgNPs differed slightly. The accumulation of sugars increases with fruit ripening via the hydrolysis of complex carbohydrates to simple sugars during storage due to metabolic activities. Coating inhibits fruit ripening and the transition of complex carbohydrates into simple sugars [71]. In other words, changes in fruit biochemical activity accompany fruit ripening; the gradual increase in total sugar content during fruit storage results from the hydrolysis of insoluble polysaccharides to soluble sugars [72]. The rapid change in total sugars of the control treatment can be explained by the mango fruit respiratory burst, which is distinguished by major changes in fruit biochemical activity, leading to a decrease in starch content and an increase in sugar content [73]. The increase in sugar content has a strong positive relationship with some physical parameters such as weight loss and respiration rate. Conversely, sugar content was negatively correlated with titratable acidity and with pulp firmness (Table S2, Supplementary Materials). Silva et al. [58] highlighted that fruit coating treatments reduced respiratory activity and ethylene production, which slows down the ripening process, delays the climacteric peak, and increases fruit storage life. During the storage time, the effect of AgNPs on the suppressed production of ethylene, the critical factor for fruit ripening, may be attributed to the decomposition or oxidation of ethylene to water and carbon dioxide [74]. 


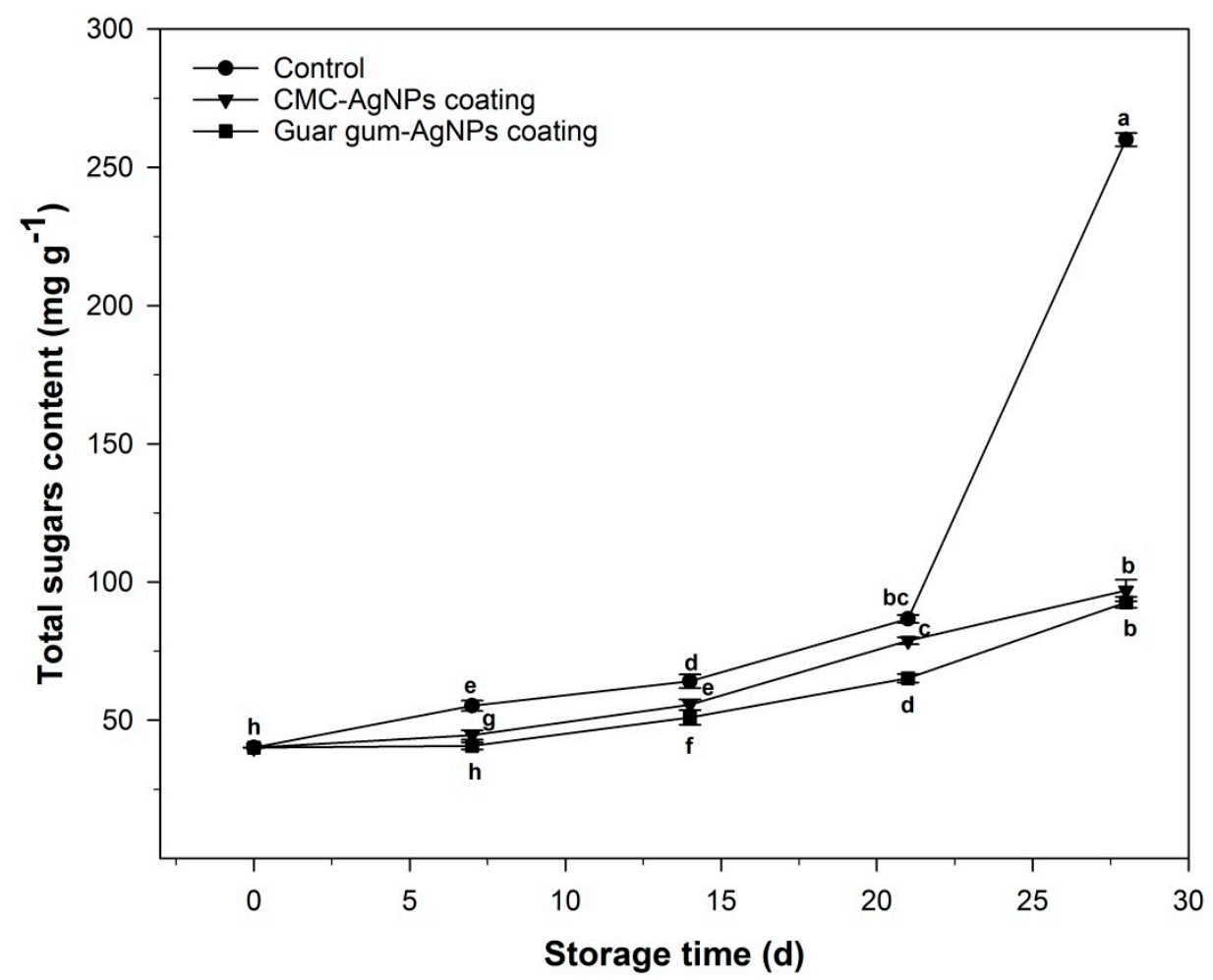

Figure 11. Effect of CMC-AgNP and guar gum-AgNP coatings on total sugar content of "Seddik" mango fruit stored at $13{ }^{\circ} \mathrm{C}$ for 4 weeks. Vertical bars represent the SE of means. Means with the same letter are not significantly different according to Duncan's multiple range test $(\alpha \leq 0.05)$.

\subsubsection{Total Carotenoid Content}

As ripening progressed in all fruits, a steady increase in carotenoid content was noted, but the rate was slower in coated fruits (Figure 12). Statistical analysis showed significant differences among sampling dates, coating treatments, and their interaction. The regression analysis showed that the total carotenoid content increased linearly with time. The slope of the regression equations revealed that accumulation of carotenoids was slower in fruits coated with guar gum-AgNPs $\left(\beta_{1}=0.553 ; R^{2}=0.9386\right)$ and CMC-AgNPs $\left(\beta_{1}=0.6817\right.$; $\left.R^{2}=0.9626\right)$ than the control treatment $\left(\beta_{1}=1.052 ; R^{2}=0.9634\right)$ (Table S1, Supplementary Materials). The increase in carotenoid content was significantly lower $(\alpha \leq 0.05)$ for fruit coated with CMC-AgNPs and guar gum-AgNPs than for uncoated ones. It seems that the guar gum-AgNP coating delayed synthesis and accumulation of carotenoids more than in fruits coated with CMC-AgNPs. Control mangoes significantly showed the highest carotenoids ( $\left.31.79 \mu \mathrm{g} \cdot \mathrm{g}^{-1}\right)$ after 4 weeks of the storage period. The mango fruit ripening process involves a series of biochemical reactions resulting in developing pigments via carotenoid biosynthesis [5]. According to the correlation analysis, total carotenoid content, which reflects fruit pulp color, had a positive correlation with total sugar content, respiration rate, and TSS (Table S2, Supplementary Materials). Postharvest treatments that control carotenoid biosynthesis and maintain the fruit color can delay fruit ripening [40]. The delay in the ripening of the coated fruit may be attributable to the modified internal atmosphere of the coated fruit, which decreases chlorophyll degradation and/or carotenoid biosynthesis [8,9]. Polysaccharide-based composite coatings have synergistic effects on color retention by delaying the development of coloring pigments in mango fruit $[38,67]$. 


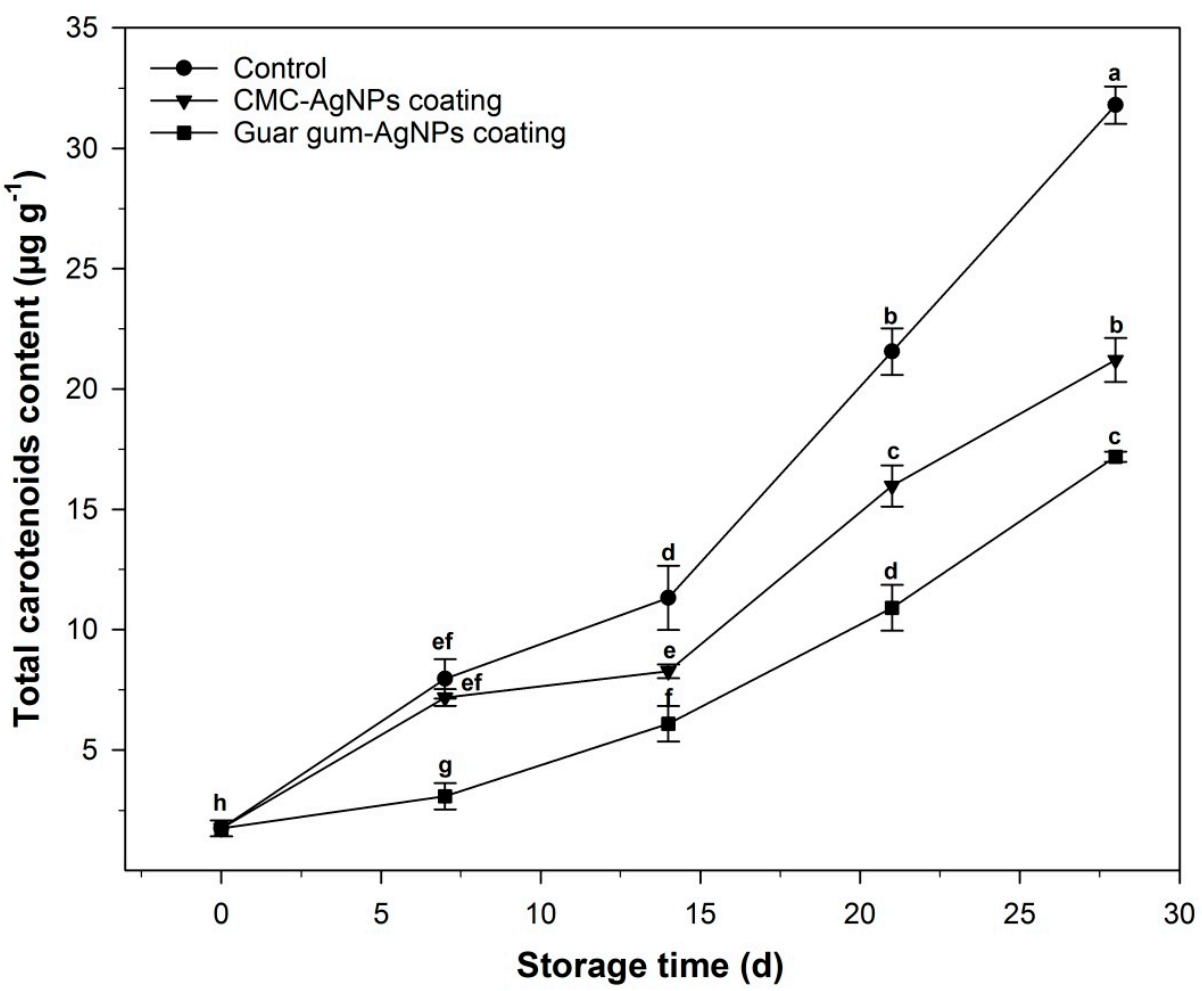

Figure 12. Effect of CMC-AgNP and guar gum-AgNP coatings on total carotenoid content of "Seddik" mango fruit stored at $13{ }^{\circ} \mathrm{C}$ for 4 weeks. Vertical bars represent the SE of means. Means with the same letter are not significantly different according to Duncan's multiple range test $(\alpha \leq 0.05)$.

\subsubsection{Determination of Total Silver Concentration}

The CMC-AgNP and guar gum-AgNP emulsions formed a thin layer after coating application on the fruit surface when the water evaporated, leaving silver nanoparticles evenly distributed in the coating matrix [35]. It is worth mentioning that the silver traces in fruit pulp samples did not exist at 14 and 28 days after treatment (data not shown). This result indicates that no nanoparticle penetration occurred through the fruit tissues.

\subsection{Principal Component Analysis (PCA)}

PCA was performed to assess the effect of coating treatments on quality parameters of "Seddik" mango fruits during cold storage (Figure 13). The first two principal components (PCs) represented $97.02 \%$ of the total variability $(\mathrm{PC} 1=90.22 \%$ and $\mathrm{PC} 2=6.80 \%$ ), with respect to coating treatments over the storage period of 28 days at $13{ }^{\circ} \mathrm{C}$. The multivariate space of PC1 and PC2 showed that the fruit quality parameters were differently influenced by treatments during storage as highlighted in the score plot of the first two principal components. Early sampling dates (days 0,7 , and 14) were clearly separated as located on the left side of the PC1 axis, while days 21 and 28 were located on the right side of the same axis. Shifts in the PC average values from negative (days 0,7 , and 14) to positive (days 21 and 28) were observed with advances in storage time for coated and uncoated mango fruits. Uncoated fruits (control) correlated positively with weight loss, respiration rate, TSS, sugar and carotenoid content and negatively with titratable acidity and firmness. Shifting from negative to positive values in PC1, mango fruits showed a general increase in weight loss, respiration rate, TSS, and total sugars combined with a decline in titratable acidity and firmness as key indicators of fruit ripening velocity. Uncoated fruits showed a higher shift in PC score values compared to coated fruits, and lower average PC scores were observed with guar gum-AgNP-coated fruits. Furthermore, the ripening rate in coated fruits after 21 days of cold storage was comparable to that of uncoated fruits at 14 days according to measured quality parameters, indicating that coating treatments 
had the ability to delay ripening of "Seddik" mango fruits with more efficiency for guar gum-AgNPs than CMC-AgNPs.

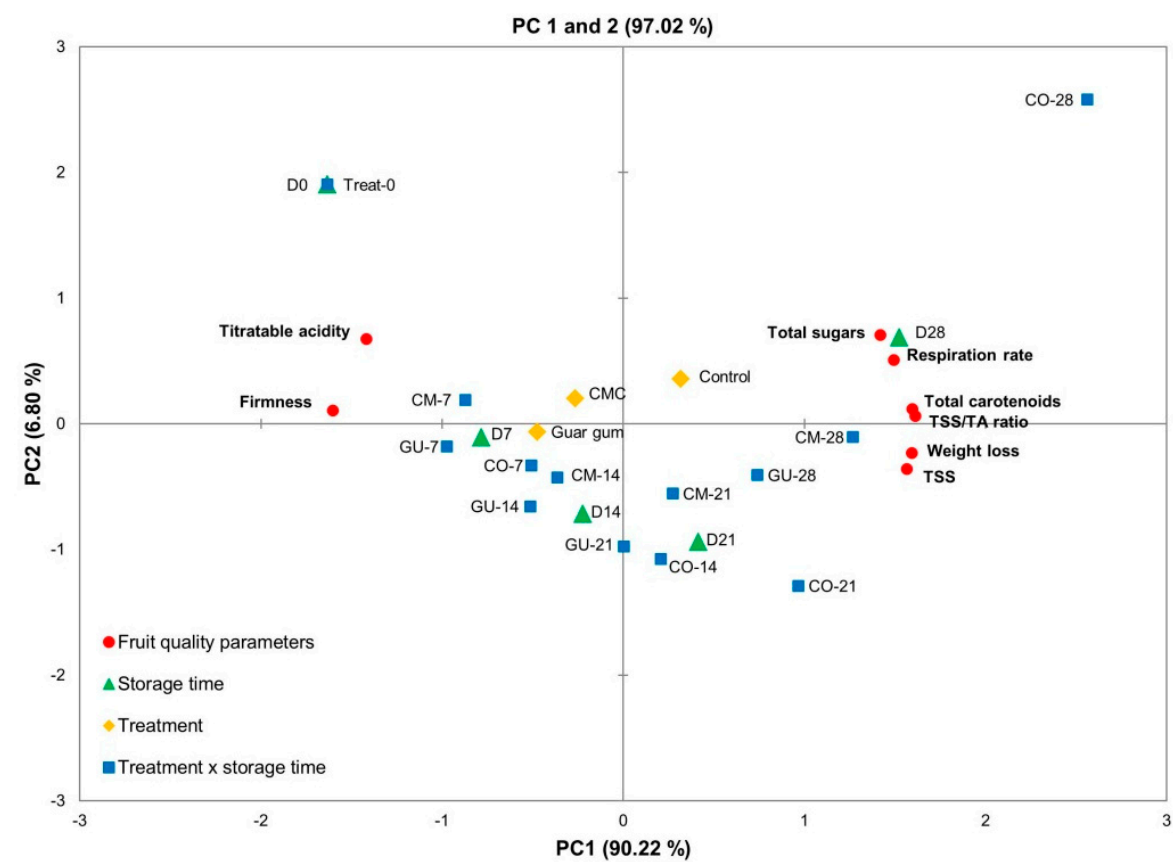

Figure 13. Principal component (PC) analysis (PC1: 90.2\%, PC2: 6.8\%) of the quality parameters of "Seddik" mango fruits over 28 days of storage period at $13{ }^{\circ} \mathrm{C}$. D: day, CO: uncoated fruits, CM: CMC-AgNP-coated fruits, GU: guar gum-AgNP-coated fruits; numbers $(0,7,14,21$, and 28$)$ refer to the sampling dates.

\section{Conclusions}

In the present study, synthesized edible nanoparticle coatings were proven to be effective alternative treatments to enhance the postharvest life of "Seddik" mango fruits. $\mathrm{CMC}$ and guar gum can be used effectively to improve the stability and mobility of AgNPs. $\mathrm{CMC}$ has anionic and reducing properties which can be used as a stabilizing agent for silver nanoparticles. Guar gum is also an excellent stabilizer and a magnificent surface capping agent due to its strong tendency to form hydrogen bonds in water. Therefore, coating with CMC- or guar gum-containing silver nanoparticles affected qualities such as the weight loss, firmness, and respiration rate of mango fruits. The CMC-AgNP and guar gum-AgNP coatings reduced the rate of fruit respiration, which influenced the other parameters of quality during storage at $13{ }^{\circ} \mathrm{C}$ compared to the uncoated fruits. Coatings also reduced the loss of mango fruit fresh weight and firmness. Increases in total soluble solids, total sugars, and total carotenoids in the coated fruit were controlled and slowed down. It should be emphasized that no traces of silver were detected in the mango fruit pulp coated with CMC- and guar gum-containing silver nanoparticles. These results suggest that the application of CMC- or guar gum-based AgNP coatings can be used efficiently to retard the ripening and prolong the postharvest life of mango fruit.

Supplementary Materials: The following are available online at https: / www.mdpi.com/2311-7 $524 / 7 / 3 / 44 / s 1$, Table S1. Linear regression analysis of changes in quality parameters of "Seddik" mango fruit stored at $13{ }^{\circ} \mathrm{C}$; Table S2. Correlation matrix between different quality parameters in "Seddik" mango fruit stored for 28 days at $13{ }^{\circ} \mathrm{C}$. Correlation coefficients were calculated by Pearson correlations at significant levels $(P \leq 0.05$ and $P \leq 0.01)$. 
Author Contributions: Conceptualization, I.H.; funding acquisition, I.H.; visualization, I.H. and M.A.-E.; project administration, I.H.; investigation, I.H., N.Z., B.M., A.A., and M.A.-E.; methodology, M.A.; resources, A.A. and M.A.-E.; data curation, N.Z. and B.M.; writing-original draft preparation, M.A., N.Z., and B.M.; formal analysis, M.A.-E.; writing-review and editing, I.H., A.A., and M.A.-E.; supervision, I.H. All authors have read and agreed to the published version of the manuscript.

Funding: This research was funded and supported by the Science, Technology, and Innovation Funding Authority (STIFA), under grant (STDF-YRG, No. 33528).

Acknowledgments: The authors would like to express special gratitude to the Science and Technology Development Fund (STDF)—Science, Technology, and Innovation Funding Authority (STIFA) for funding and the Faculty of Agriculture, Cairo University for all facilities during this work.

Conflicts of Interest: The authors declare no conflict of interest.

\section{References}

1. Sane, V.A.; Chourasia, A.; Nath, P. Softening in mango (Mangifera indica cv. Dashehari) is correlated with the expression of an early ethylene responsive, ripening related expansin gene, MiExpA1. Postharvest Biol. Technol. 2005, 38, 223-230. [CrossRef]

2. Ribeiro, S.M.R.; Schieber, A. Bioactive compounds in mango (Mangifera indica L.). In Bioactive Foods in Promoting Health; Watson, R.R., Preedy, V.R., Eds.; Academic Press: London, UK, 2010; pp. 507-523. [CrossRef]

3. Jahurul, M.H.A.; Zaidul, I.S.M.; Ghafoor, K.; Al-Juhaimi, F.Y.; Nyam, K.L.; Norulaini, N.A.N.; Sahena, F.; Omar, A.M. Mango (Mangifera indica L.) by-products and their valuable components: A review. Food Chem. 2015, 183, 173-180. [CrossRef]

4. Kader, A.A. Quality and safety factors: Definition and evaluation for fresh horticultural crops. In Postharvest Technology of Horticultural Crops, 3rd ed.; Kader, A.A., Ed.; University of California Agriculture and Natural Resources: Davis, CA, USA, 2002; pp. 279-285.

5. Lalel, H.J.D.; Singh, Z.; Tan, S.C.; Agustí, M. Maturity stage at harvest affects fruit ripening, quality and biosynthesis of aroma volatile compounds in 'Kensington Pride' mango. J. Hortic. Sci. Biotechnol. 2003, 78, 225-233. [CrossRef]

6. Sivakumar, D.; Jiang, Y.; Yahia, E.M. Maintaining mango (Mangifera indica L.) fruit quality during the export chain. Food Res. Int. 2011, 44, 1254-1263. [CrossRef]

7. Cárdenas-Coronel, W.G.; Velez-de la Rocha, R.; Siller-Cepeda, J.H.; Osuna-Enciso, T.; Muy-Rangel, M.D.; Sañudo-Barajas, J.A. Changes in the composition of starch, pectin and hemicellulose during ripening of mango (Mangifera indica cv. Kent). Rev. Chapingo Ser. Hortic. 2012, 18, 5-19. [CrossRef]

8. Carrillo-Lopez, A.; Ramirez-Bustamante, F.; Valdez-Torres, J.B.; Rojas-Villegas, R.; Yahia, E.M. Ripening and quality changes in mango fruit as affected by coating with an edible film. J. Food Qual. 2000, 23, 479-486. [CrossRef]

9. Hoa, T.T.; Ducamp, M.N.; Lebrun, M.; Baldwin, E.A. Effect of different coating treatments on the quality of mango fruit. J. Food Qual. 2002, 25, 471-486. [CrossRef]

10. Ridoutt, B.G.; Juliano, P.; Sanguansri, P.; Sellahewa, J. The water footprint of food waste: Case study of fresh mango in Australia. J. Clean. Prod. 2010, 18, 1714-1721. [CrossRef]

11. López-Mora, L.I.; Gutiérrez-Martínez, P.; Bautista-Baños, S.; Jiménez-García, L.F.; Zavaleta-Mancera, H.A. Evaluation of antifungal activity of chitosan in Alternaria alternata and in the quality of 'Tommy Atkins' mango during storage. Rev. Chapingo Ser. Hortic. 2013, 19, 315-331. [CrossRef]

12. Hassan, B.; Chatha, S.A.S.; Hussain, A.I.; Zia, K.M.; Akhtar, N. Recent advances on polysaccharides, lipids and protein based edible films and coatings: A review. Int. J. Biol. Macromol. 2018, 109, 1095-1107. [CrossRef]

13. Nair, M.S.; Saxena, A.; Kaur, C. Effect of chitosan and alginate based coatings enriched with pomegranate peel extract to extend the postharvest quality of guava (Psidium guajava L.). Food Chem. 2018, 240, 245-252. [CrossRef]

14. Maftoonazad, N.; Ramaswamy, H.S.; Marcotte, M. Shelf-life extension of peaches through sodium alginate and methyl cellulose edible coatings. Int. J. Food Sci. Technol. 2008, 43, 951-957. [CrossRef]

15. Cazón, P.; Velazquez, G.; Ramírez, J.A.; Vázquez, M. Polysaccharide-based films and coatings for food packaging: A review. Food Hydrocoll. 2017, 68, 136-148. [CrossRef]

16. Chen, C.; Peng, X.; Zeng, R.; Wan, C.; Chen, M.; Chen, J. Physiological and biochemical responses in cold-stored citrus fruits to carboxymethyl cellulose coating containing ethanol extract of Impatiens balsamina L. stems. J. Food Process. Preserv. 2017, 41, e12999. [CrossRef]

17. Panahirad, S.; Naghshiband-Hassani, R.; Ghanbarzadeh, B.; Zaare-Nahandi, F.; Mahna, N. Shelf life quality of plum fruits (Prunus domestica L.) improves with carboxymethylcellulose-based edible coating. HortScience 2019, 54, 505-510. [CrossRef]

18. Ribeiro, C.; Vicente, A.A.; Teixeira, J.A.; Miranda, C. Optimization of edible coating composition to retard strawberry fruit senescence. Postharvest Biol. Technol. 2007, 44, 63-70. [CrossRef]

19. Candido, R.G.; Gonçalves, A.R. Synthesis of cellulose acetate and carboxymethylcellulose from sugarcane straw. Carbohydr. Polym. 2016, 152, 679-686. [CrossRef] 
20. Malmiri, H.J.; Osman, A.; Tan, C.P.; Abdul Rahman, R. Developing a new antimicrobial edible coating formulation based on carboxymethylcellulose-silver nanoparticles for tropical fruits and an in vitro evaluation of its antimicrobial properties. Acta Hortic. 2013, 1012, 705-710. [CrossRef]

21. Vyas, P.B.; Gol, N.B.; Rao, T.R. Postharvest quality maintenance of papaya fruit using polysaccharide-based edible coatings. Int. J. Fruit Sci. 2014, 14, 81-94. [CrossRef]

22. Arnon, H.; Granit, R.; Porat, R.; Poverenov, E. Development of polysaccharides-based edible coatings for citrus fruits: A layer-by-layer approach. Food Chem. 2015, 166, 465-472. [CrossRef]

23. Roberts, K.T. The physiological and rheological effects of foods supplemented with guar gum. Food Res. Int. 2011, 44, 1109-1114. [CrossRef]

24. Thombare, N.; Jha, U.; Mishra, S.; Siddiqui, M.Z. Guar gum as a promising starting material for diverse applications: A review. Int. J. Biol. Macromol. 2016, 88, 361-372. [CrossRef]

25. Ruelas-Chacon, X.; Contreras-Esquivel, J.C.; Montañez, J.; Aguilera-Carbo, A.F.; Reyes-Vega, M.L.; Peralta-Rodriguez, R.D.; Sanchéz-Brambila, G. Guar gum as an edible coating for enhancing shelf-life and improving postharvest quality of roma tomato (Solanum lycopersicum L.). J. Food Qual. 2017, 2017. [CrossRef]

26. Naeem, A.; Abbas, T.; Ali, T.M.; Hasnain, A. Effect of guar gum coatings containing essential oils on shelf life and nutritional quality of green-unripe mangoes during low temperature storage. Int. J. Biol. Macromol. 2018, 113, 403-410. [CrossRef]

27. Saberi, B.; Golding, J.B.; Marques, J.R.; Pristijono, P.; Chockchaisawasdee, S.; Scarlett, C.J.; Stathopoulos, C.E. Application of biocomposite edible coatings based on pea starch and guar gum on quality, storability and shelf life of 'Valencia' oranges. Postharvest Biol. Technol. 2018, 137, 9-20. [CrossRef]

28. An, J.; Zhang, M.; Wang, S.; Tang, J. Physical, chemical and microbiological changes in stored green asparagus spears as affected by coating of silver nanoparticles-PVP. LWT Food Sci. Technol. 2008, 41, 1100-1107. [CrossRef]

29. Rao, J.; McClements, D.J. Food-grade microemulsions and nanoemulsions: Role of oil phase composition on formation and stability. Food Hydrocoll. 2012, 29, 326-334. [CrossRef]

30. Kumar, N.; Kaur, P.; Devgan, K.; Attkan, A.K. Shelf life prolongation of cherry tomato using magnesium hydroxide reinforced bio-nanocomposite and conventional plastic films. J. Food Process. Preserv. 2020, 44, e14379. [CrossRef]

31. Gammariello, D.; Conte, A.; Buonocore, G.G.; Del Nobile, M.A. Bio-based nanocomposite coating to preserve quality of Fior di latte cheese. J. Dairy Sci. 2011, 94, 5298-5304. [CrossRef]

32. Kim, J.S.; Kuk, E.; Yu, K.N.; Kim, J.H.; Park, S.J.; Lee, H.J.; Kim, S.H.; Park, Y.K.; Park, Y.H.; Hwang, C.Y.; et al. Antimicrobial effects of silver nanoparticles. Nanomed. Nanotechnol. Biol. Med. 2007, 3, 95-101. [CrossRef]

33. Lee, S.; Lee, J.; Kim, K.; Sim, S.J.; Gu, M.B.; Yi, J.; Lee, J. Eco-toxicity of commercial silver nanopowders to bacterial and yeast strains. Biotechnol. Bioprocess Eng. 2009, 14, 490-495. [CrossRef]

34. De Azeredo, H.M. Nanocomposites for food packaging applications. Food Res. Int. 2009, 42, 1240-1253. [CrossRef]

35. Shah, S.W.A.; Jahangir, M.; Qaisar, M.; Khan, S.A.; Mahmood, T.; Saeed, M.; Farid, A.; Liaquat, M. Storage stability of kinnow fruit (Citrus reticulata) as affected by CMC and guar gum-based silver nanoparticle coatings. Molecules 2015, 20, 22645-22661. [CrossRef]

36. Pelissari, F.M.; Andrade-Mahecha, M.M.; do Amaral Sobral, P.J.; Menegalli, F.C. Nanocomposites based on banana starch reinforced with cellulose nanofibers isolated from banana peels. J. Colloid Interface Sci. 2017, 505, 154-167. [CrossRef]

37. Tibolla, H.; Pelissari, F.M.; Martins, J.T.; Vicente, A.A.; Menegalli, F.C. Cellulose nanofibers produced from banana peel by chemical and mechanical treatments: Characterization and cytotoxicity assessment. Food Hydrocoll. 2018, 75, 192-201. [CrossRef]

38. Shah, S.; Hashmi, M.S. Chitosan-aloe vera gel coating delays postharvest decay of mango fruit. Hortic. Environ. Biotechnol. 2020, 61, 279-289. [CrossRef]

39. Pristijono, P.; Golding, J.B.; Bowyer, M.C. Postharvest UV-C treatment, followed by storage in a continuous low-level ethylene atmosphere, maintains the quality of 'Kensington pride' mango fruit stored at $20^{\circ} \mathrm{C}$. Horticulturae 2019, 5, 1. [CrossRef]

40. Liu, S.; Huang, H.; Huber, D.J.; Pan, Y.; Shi, X.; Zhang, Z. Delay of ripening and softening in 'Guifei' mango fruit by postharvest application of melatonin. Postharvest Biol. Technol. 2020, 163, 111136. [CrossRef]

41. Khaliq, G.; Mohamed, M.T.M.; Ali, A.; Ding, P.; Ghazali, H.M. Effect of gum arabic coating combined with calcium chloride on physico-chemical and qualitative properties of mango (Mangifera indica L.) fruit during low temperature storage. Sci. Hortic. 2015, 190, 187-194. [CrossRef]

42. Dubois, M.; Gilles, K.A.; Hamilton, J.K.; Rebers, P.T.; Smith, F. Colorimetric method for determination of sugars and related substances. Anal. Chem. 1956, 28, 350-356. [CrossRef]

43. Jensen, A. Chlorophylls and carotenoids. In Handbook of Phycological Methods: Physiological and Biochemical Methods; Hellebust, J.A., Craigie, J.S., Eds.; Cambridge University Press: Cambridge, UK, 1978; pp. 59-70.

44. Altundag, H.; Tuzen, M. Comparison of dry, wet and microwave digestion methods for the multi element determination in some dried fruit samples by ICP-OES. Food Chem. Toxicol. 2011, 49, 2800-2807. [CrossRef]

45. Zhang, Z.; Kong, F.; Vardhanabhuti, B.; Mustapha, A.; Lin, M. Detection of engineered silver nanoparticle contamination in pears. J. Agric. Food Chem. 2012, 60, 10762-10767. [CrossRef]

46. Duncan, D.B. Multiple range and multiple F tests. Biometrics 1955, 11, 1-42. [CrossRef]

47. Selvi, B.C.G.; Madhavan, J.; Santhanam, A. Cytotoxic effect of silver nanoparticles synthesized from Padina tetrastromatica on breast cancer cell line. Adv. Nat. Sci. Nanosci. Nanotechnol. 2016, 7, 035015. [CrossRef] 
48. Shousha, W.G.; Aboulthana, W.M.; Salama, A.H.; Saleh, M.H.; Essawy, E.A. Evaluation of the biological activity of Moringa oleifera leaves extract after incorporating silver nanoparticles, in vitro study. Bull. Natl. Res. Cent. 2019, 43, 212. [CrossRef]

49. Bar, H.; Bhui, D.K.; Sahoo, G.P.; Sarkar, P.; De, S.P.; Misra, A. Green synthesis of silver nanoparticles using latex of Jatropha curcas. Colloids Surf. A Physicochem. Eng. Asp. 2009, 339, 134-139. [CrossRef]

50. Nayagam, V.; Gabriel, M.; Palanisamy, K. Green synthesis of silver nanoparticles mediated by Coccinia grandis and Phyllanthus emblica: A comparative comprehension. Appl. Nanosci. 2018, 8, 205-219. [CrossRef]

51. Silvert, P.Y.; Herrera-Urbina, R.; Tekaia-Elhsissen, K. Preparation of colloidal silver dispersions by the polyol process. J. Mater. Chem. 1997, 7, 293-299. [CrossRef]

52. Aziz, S.B.; Abidin, Z.H.Z.; Arof, A.K. Influence of silver ion reduction on electrical modulus parameters of solid polymer electrolyte based on chitosan-silver triflate electrolyte membrane. Express Polym. Lett. 2010, 4, 300-310. [CrossRef]

53. Jayasekara, R.; Harding, I.; Bowater, I.; Christie, G.B.Y.; Lonergan, G.T. Preparation, surface modification and characterisation of solution cast starch PVA blended films. Polym. Test. 2004, 23, 17-27. [CrossRef]

54. Whelan, A.M.; Brennan, M.E.; Blau, W.J.; Kellya, J.M. Enhanced third-order optical nonlinearity of silver nanoparticles with a tunable surface plasmon resonance. J. Nanosci. Nanotechnol. 2004, 4, 66-68. [CrossRef] [PubMed]

55. Chang, C.; Duan, B.; Cai, J.; Zhang, L. Superabsorbent hydrogels based on cellulose for smart swelling and controllable delivery. Eur. Polym. J. 2010, 46, 92-100. [CrossRef]

56. Yang, S.; Fu, S.; Liu, H.; Zhou, Y.; Li, X. Hydrogel beads based on carboxymethyl cellulose for removal heavy metal ions. J. Appl. Polym. Sci. 2011, 119, 1204-1210. [CrossRef]

57. Pandey, S.; Goswami, G.K.; Nanda, K.K. Green synthesis of biopolymer-silver nanoparticle nanocomposite: An optical sensor for ammonia detection. Int. J. Biol. Macromol. 2012, 51, 583-589. [CrossRef]

58. Silva, G.M.C.; Silva, W.B.; Medeiros, D.B.; Salvador, A.R.; Cordeiro, M.H.M.; da Silva, N.M.; Santana, D.B.; Mizobutsi, G.P. The chitosan affects severely the carbon metabolism in mango (Mangifera indica L. cv. Palmer) fruit during storage. Food Chem. 2017, 237, 372-378. [CrossRef]

59. Wills, R.; Golding, J. Postharvest: An Introduction to the Physiology and Handling of Fruit and Vegetables, 6th ed.; CABI: Wallingford, UK, 2016; 293p. [CrossRef]

60. Nawab, A.; Alam, F.; Hasnain, A. Mango kernel starch as a novel edible coating for enhancing shelf-life of tomato (Solanum lycopersicum) fruit. Int. J. Biol. Macromol. 2017, 103, 581-586. [CrossRef]

61. Gardesh, A.S.K.; Badii, F.; Hashemi, M.; Ardakani, A.Y.; Maftoonazad, N.; Gorji, A.M. Effect of nanochitosan based coating on climacteric behavior and postharvest shelf-life extension of apple cv. Golab Kohanz. LWT Food Sci. Technol. 2016, 70, 33-40. [CrossRef]

62. Ali, A.; Maqbool, M.; Ramachandran, S.; Alderson, P.G. Gum arabic as a novel edible coating for enhancing shelf-life and improving postharvest quality of tomato (Solanum lycopersicum L.) fruit. Postharvest Biol. Technol. 2010, 58, 42-47. [CrossRef]

63. Elsheshetawy, H.E.; Mossad, A.; Elhelew, W.K.; Farina, V. Comparative study on the quality characteristics of some Egyptian mango cultivars used for food processing. Ann. Agric. Sci. 2016, 61, 49-56. [CrossRef]

64. Deng, Z.; Jung, J.; Simonsen, J.; Zhao, Y. Cellulose nanomaterials emulsion coatings for controlling physiological activity, modifying surface morphology, and enhancing storability of postharvest bananas (Musa acuminate). Food Chem. 2017, 232, 359-368. [CrossRef] [PubMed]

65. Dave, R.K.; Rao, T.R.; Nandane, A.S. Improvement of post-harvest quality of pear fruit with optimized composite edible coating formulations. J. Food Sci. Technol. 2017, 54, 3917-3927. [CrossRef]

66. Chi, H.; Song, S.; Luo, M.; Zhang, C.; Li, W.; Li, L.; Qin, Y. Effect of PLA nanocomposite films containing bergamot essential oil, $\mathrm{TiO}_{2}$ nanoparticles, and Ag nanoparticles on shelf life of mangoes. Sci. Hortic. 2019, 249, 192-198. [CrossRef]

67. Kittur, F.S.; Saroja, N.; Tharanathan, R. Polysaccharide-based composite coating formulations for shelf-life extension of fresh banana and mango. Eur. Food Res. Technol. 2001, 213, 306-311. [CrossRef]

68. Ali, M.; Ahmed, A.; Shah, S.W.A.; Mehmood, T.; Abbasi, K.S. Effect of silver nanoparticle coatings on physicochemical and nutraceutical properties of loquat during postharvest storage. J. Food Process. Preserv. 2020, 44, e14808. [CrossRef]

69. Gol, N.B.; Chaudhari, M.L.; Rao, T.V.R. Effect of edible coatings on quality and shelf life of carambola (Averrhoa carambola L.) fruit during storage. J. Food Sci. Technol. 2015, 52, 78-91. [CrossRef]

70. Batista-Silva, W.; Nascimento, V.L.; Medeiros, D.B.; Nunes-Nesi, A.; Ribeiro, D.M.; Zsögön, A.; Araújo, W.L. Modifications in organic acid profiles during fruit development and ripening: Correlation or causation? Front. Plant Sci. 2018, 9, 1689. [CrossRef]

71. Ullah, A.; Abbasi, N.A.; Shafique, M.; Qureshi, A.A. Influence of edible coatings on biochemical fruit quality and storage life of bell pepper cv. "Yolo Wonder". J. Food Qual. 2017, 2017. [CrossRef]

72. Selvaraj, Y.; Kumar, R.; Pal, D.K. Changes in sugars, organic acids, amino acids, lipid constituents and aroma characteristics of ripening mango (Mangifera indica L.) fruit. J. Food Sci. Technol. 1989, 26, 308-313.

73. Osorio, S.; Scossa, F.; Fernie, A. Molecular regulation of fruit ripening. Front. Plant Sci. 2013, 4, 198. [CrossRef] [PubMed]

74. Li, H.; Li, F.; Wang, L.; Sheng, J.; Xin, Z.; Zhao, L.; Xiao, H.; Zheng, Y.; Hu, Q. Effect of nano-packing on preservation quality of Chinese jujube (Ziziphus jujuba Mill. var. inermis (Bunge) Rehd). Food Chem. 2009, 114, 547-552. [CrossRef] 